\title{
Recent molecular approaches to understanding astrocyte function in vivo
}

\author{
David Davila ${ }^{1}$, Karine Thibault ${ }^{1}$, Todd A. Fiacco ${ }^{2}{ }^{*}$ and Cendra Agulhon ${ }^{1}$ * \\ 1 Glia-Glia and Glia-Neuron Interactions Group, National Center for Scientific Research, UFR Biomedicale, Paris Descartes University, Paris, France \\ 2 Department of Cell Biology and Neuroscience, and Center for Glial-Neuronal Interactions and Program in Cellular, Molecular and Developmental Biology, \\ University of California at Riverside, Riverside, CA, USA
}

\section{Edited by:}

Carole Escartin, Molecular Imaging Research Center, France

\section{Reviewed by:}

Keith Murai, Mc Gill University, Canada Frank W. Pfrieger, National Center for Scientific Research, France

\section{*Correspondence:}

Cendra Agulhon, Glia-Glia and Glia-Neuron Interactions Group,

National Center for Scientific

Research, UFR Biomedicale, Paris

Descartes University, 45 rue des

Saints Pères, 75006 Paris, France

e-mail: cendra.agulhon@

parisdescartes.fr;

Todd A. Fiacco, Department of Cell

Biology and Neuroscience, and

Center for Glial-Neuronal Interactions

and Program in Cellular, Molecular

and Developmental Biology,

University of California Riverside, 1109

Biological Sciences Building,

Riverside, CA 92521, USA

e-mail: toddf@ucr.edu
Astrocytes are a predominant glial cell type in the nervous systems, and are becoming recognized as important mediators of normal brain function as well as neurodevelopmental, neurological, and neurodegenerative brain diseases. Although numerous potential mechanisms have been proposed to explain the role of astrocytes in the normal and diseased brain, research into the physiological relevance of these mechanisms in vivo is just beginning. In this review, we will summarize recent developments in innovative and powerful molecular approaches, including knockout mouse models, transgenic mouse models, and astrocytetargeted gene transfer/expression, which have led to advances in understanding astrocyte biology in vivo that were heretofore inaccessible to experimentation. We will examine the recently improved understanding of the roles of astrocytes - with an emphasis on astrocyte signaling - in the context of both the healthy and diseased brain, discuss areas where the role of astrocytes remains debated, and suggest new research directions.

Keywords: astrocytes, knockout mice, transgenic mice, chemogenetics, viral gene transduction, glial cell progenitors, GPCR, neuron-glia interactions

\section{INTRODUCTION}

Although astrocytes are the most abundant glial cell type in the mammalian nervous system and have emerged as crucial regulators of nervous system development, function, and health, our understanding of the physiology of astrocytes remains limited. How do astrocytes interact with neurons and other cell types of the nervous system? What are the primary functions of astrocytes in brain development, health, and disease? One challenge to address these questions is identifying the function of individual astrocytic molecules that regulate brain function. A unique approach to investigate the molecular basis of astrocyte activity consists of manipulating the genome of higher organisms. The mouse represents a great animal model that has been used extensively for genetic manipulation in neuroscience, leading to understanding of neuronal functions in unprecedented detail. A concerted effort in recent years to develop genetic approaches to study astrocytes is guiding the field into new territory and improving our understanding of interactions between neurons and astrocytes. Here we will review techniques for genetic manipulation of astrocytes and highlight the most recent innovative and elegant approaches that are providing insight into fundamental roles of astrocytes in pathophysiology in vivo. In particular, we will describe the main molecular approaches used in this field, including knockout (KO) mouse models, transgenic mouse models, and astrocyte-targeted gene transfer and expression using adeno-associated viral (AAV) or in utero electroporation (IUE) approaches. We will also touch on a remarkable recent study involving engraftment of genetically modified human glial progenitors into the mouse brain, providing insight into the role of human astrocytes in the unique cognitive abilities of the human brain. The present review does not attempt to be comprehensive; rather it highlights certain major themes and areas of recent progress on the roles of astrocytes in brain function, with an emphasis on astrocyte signaling and in vivo studies. For complementary reviews on astrocyte function in health and disease with an emphasis on molecular approaches, readers are directed to (Fiacco et al., 2009b; Figueiredo et al., 2011; Agulhon et al., 2012; Nedergaard and Verkhratsky, 2012; Clarke and Barres, 2013; Freeman and Rowitch, 2013; Tong et al., 2013), as well as the other contributions to this special topic.

\section{STUDYING ASTROCYTE FUNCTION THROUGH GENE DISRUPTION}

The elimination of one or more specific genes in an animal model is a reliable and widespread approach to discovering the function of specific proteins and the cell types expressing them. Many genes have been identified, isolated, and subsequently manipulated to fully or conditionally suppress their expression (Sikorski and Peters, 1997; Grimm, 2006; Vogel, 2007). These molecular 
developments represent powerful tools that can be used in vivo to aid in discovering the role of astrocytes in the healthy and diseased brain.

\section{FULL (CONSTITUTIVE) KNOCKOUT MOUSE MODELS}

As research into astroglia physiology in vivo is still a newly developing field, much information can be gleaned from the elimination of a gene or the deletion of a functional domain of a protein in astrocytes to shed light on the function of both the targeted gene and astrocytes in general. The process of generating a new line of $\mathrm{KO}$ mice is laborious, but has been refined to maximize efficiency (reviewed in Hall et al., 2009; Limaye et al., 2009). Once the desired gene is identified, gene targeting can be used to generate a $\mathrm{KO}$ mouse. A targeting vector containing a neomycin-resistant marker is inserted into embryonic stem (ES) cells via electroporation and is introduced into the DNA through homologous recombination, allowing complete removal of one or more exons from the gene of interest (Figure 1A). This results in the production of a mutated or truncated protein or, more often, no protein at all. ES cells that do not take up the foreign construct are killed through exposure to neomycin, and those that have successfully replaced the gene or the exons of this gene survive and are subsequently microinjected into mouse blastocysts, which are then grown in surrogate mouse uteri. Strategic mating of the chimeric mice will ultimately result in a mouse with the gene globally eliminated (Capecchi, 1989; Hall et al., 2009; Limaye et al., 2009; Figure 1A).

\section{Role of GFAP in the healthy and diseased brain}

One of the first genes that was removed in astrocytes is the gene encoding glial fibrillary acidic protein (GFAP; Lewis et al., 1984; Reeves et al., 1989; Masood et al., 1993; McCall et al., 1996; Eng et al., 2000). GFAP is a member of the family of intermediate filament structural proteins, which, in the mature nervous system, is found predominantly in protoplasmic and specialized astrocytes of the central nervous system (CNS) as well as in satellite cells, non-myelinating Schwann cells, and enteric glia in the peripheral nervous system (PNS; Jessen et al., 1984; Eng, 1985; Kato et al., 1990). Outside the nervous system, GFAP has also been detected in some rare non-glial cells of the salivary glands (Achstatter et al., 1986; Gustafsson et al., 1989), fibroblasts (Hainfellner et al., 2001), myoepithelial cells (Viale et al., 1991), liver stellate cells (Gard et al., 1985), and lymphocytes (Riol et al., 1997). This protein is one of the key elements of the cytoskeleton that contributes to the morphology and motility of astrocyte processes (Fuchs and Weber, 1994; Pekny and Pekna, 2004; Gomi et al., 2010; Middeldorp and Hol, 2011) and is upregulated in reactive astrocytes (astrogliosis) in essentially any CNS pathology (Eng and Ghirnikar, 1994; Eng et al., 2000; Pekny and Nilsson, 2005; Sofroniew, 2009; Sosunov et al., 2013). During development, GFAP is expressed widely in a number of progenitor cell types giving rise to both neurons and glia. For example, GFAP-expressing radial glia in the ventricular zone (VZ) give rise to mature astrocytes, oligodendrocytes and neurons, as well as guiding subsequent migration of neurons (Gotz et al., 2002; Malatesta et al., 2003; Anthony et al., 2004; Merkle et al., 2004).

The seminal studies reporting the findings obtained with the GFAP KO mouse models were made by targeted deletion of the
GFAP gene in ES cells (Pekny et al., 1995; Liedtke et al., 1996; McCall et al., 1996) or by targeted disruption of the GFAP gene by insertion of a $L a c Z$ cassette (Gomi et al., 1995). These GFAP KO mouse lines have been used to investigate whether changes in astrocyte processes and their morphological structure can influence brain morphogenesis and function, the physiology of adjacent synapses, and functional recovery after CNS insults. The overall appearance of the GFAP KO mice is indistinguishable from wild-type mice; they develop normally and display no gross alterations in behavior or CNS morphology. This observation suggests at first that GFAP is not essential for normal brain morphogenesis and function. However, closer analyses have indicated the involvement of GFAP in a wide variety of processes. First, these mice display enhanced hippocampal long-term potentiation (LTP) and deficient cerebellar long-term depression (LTD) in acute brain slices from adult mice, suggesting that GFAP intermediate filament protein is important for astrocyte-neuronal interactions and that astrocyte processes play a vital role in modulating synaptic efficacy in the CNS (McCall et al., 1996; Shibuki et al., 1996). In agreement with the cerebellar ex vivo findings, a significant impairment of eye blink conditioning was found in the GFAP KO mice, suggesting that GFAP is required for normal communication between Bergmann glia (specialized astrocytes) and Purkinje cells during induction and maintenance of cerebellar LTD in vivo (Shibuki et al., 1996). Second, morphological and functional alterations in the blood-brain barrier (BBB), disorganization of white matter architecture and vascularization, as well as hydrocephalus were reported in 18-24 month GFAP KO mice, suggesting an involvement of GFAP in the long-term maintenance of normal BBB and CNS myelination (Liedtke et al., 1996). Third, when challenged by diverse brain injuries in vivo, the GFAP KO mice were more vulnerable to: (i) CNS mechanical trauma (Nawashiro et al., 1998; Otani et al., 2006), (ii) cerebral ischemia (Nawashiro et al., 2000; Tanaka et al., 2002), (iii) kainic acid-induced neurotoxicity (Otani et al., 2006), and (iv) autoimmune encephalomyelitis (Liedtke et al., 1998). This was indicated by: (i) increased brain hemorrhage and mortality of mice; (ii) larger cortical infarct volume and profound decrease in cerebral blood flow; (iii) neurodegeneration; and (iv) enhanced clinical course of autoimmune encephalomyelitis and lesions, respectively. Conversely, other investigators have found that suppressing astrocytic GFAP expression in reactive astrocytes increases their basal levels of glial cell derived neurotrophic factor (GDNF), leading to improvement in neuronal survival from metabolic and excitotoxic insults (Hanbury et al., 2003). Beneficial neuroprotective and regenerative effects have also been reported after hippocampal and spinal cord injuries in mice lacking both GFAP and vimentin, another astrocyte intermediate filament protein (Kinouchi et al., 2003; Menet et al., 2003; Wilhelmsson et al., 2004). Collectively, these findings suggest that the GFAP component of the astrocyte cytoskeleton plays an important role in the physiology and pathology of the nervous system. However, because GFAP is expressed in progenitor cells during development giving rise to neurons, oligodendrocytes and astrocytes, these findings have to be viewed carefully. Inducible GFAP KO strategies can be used to circumvent this problem by removing GFAP only from astrocytes after this developmental window has closed (see below). 


\section{A Full $\mathrm{KO}$}

Mouse genome

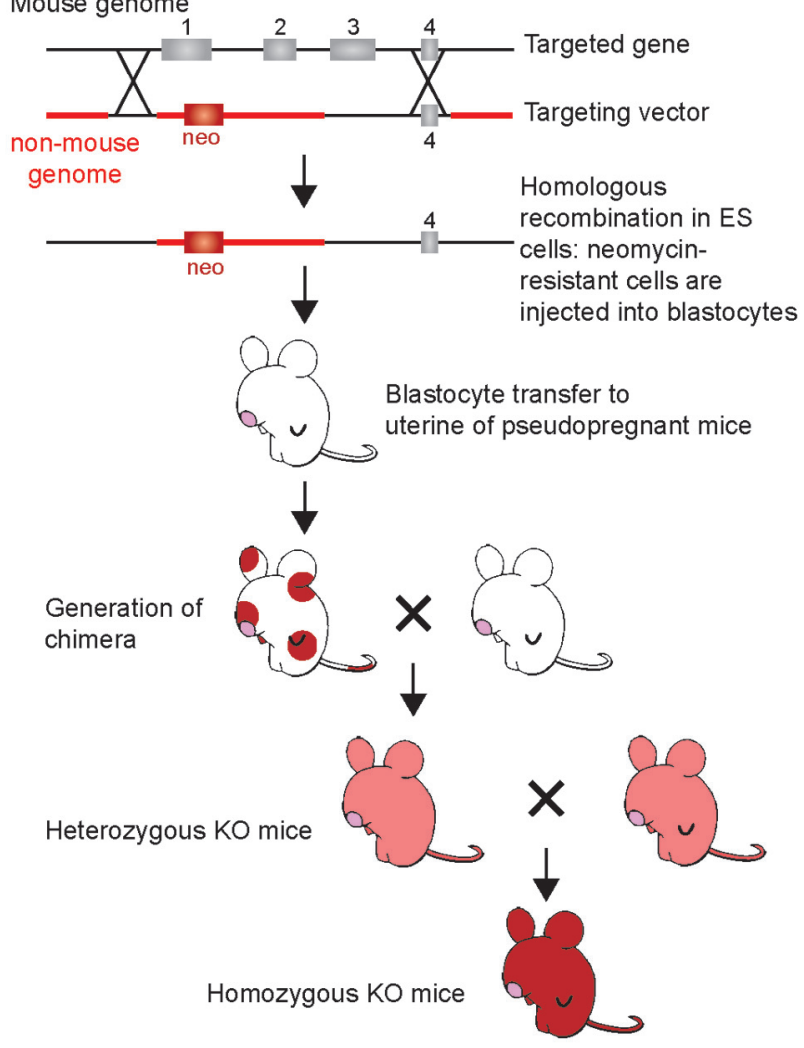

B Conditional KO

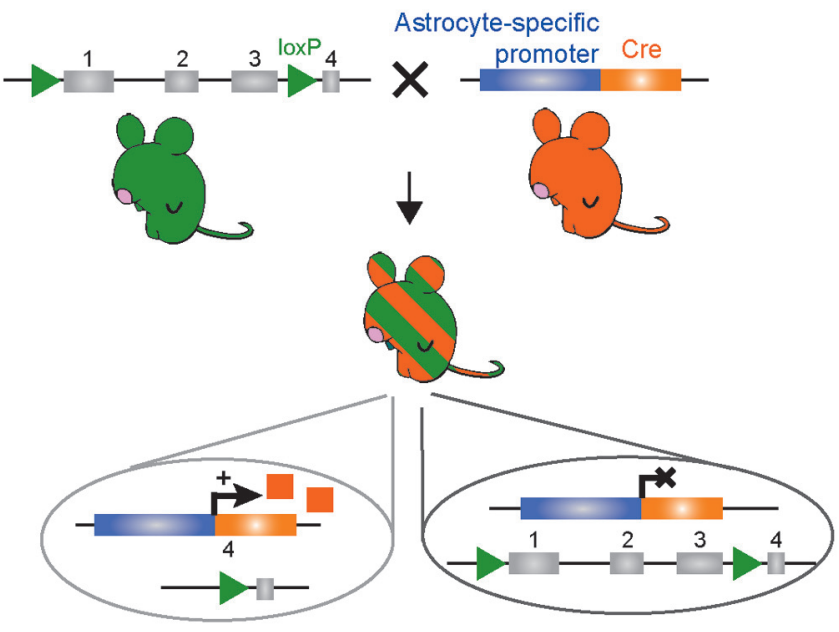

Cre-excised allele in astrocytes
Functional floxed allele in non-astrocytic cell types

\section{c Inducible conditional KO}

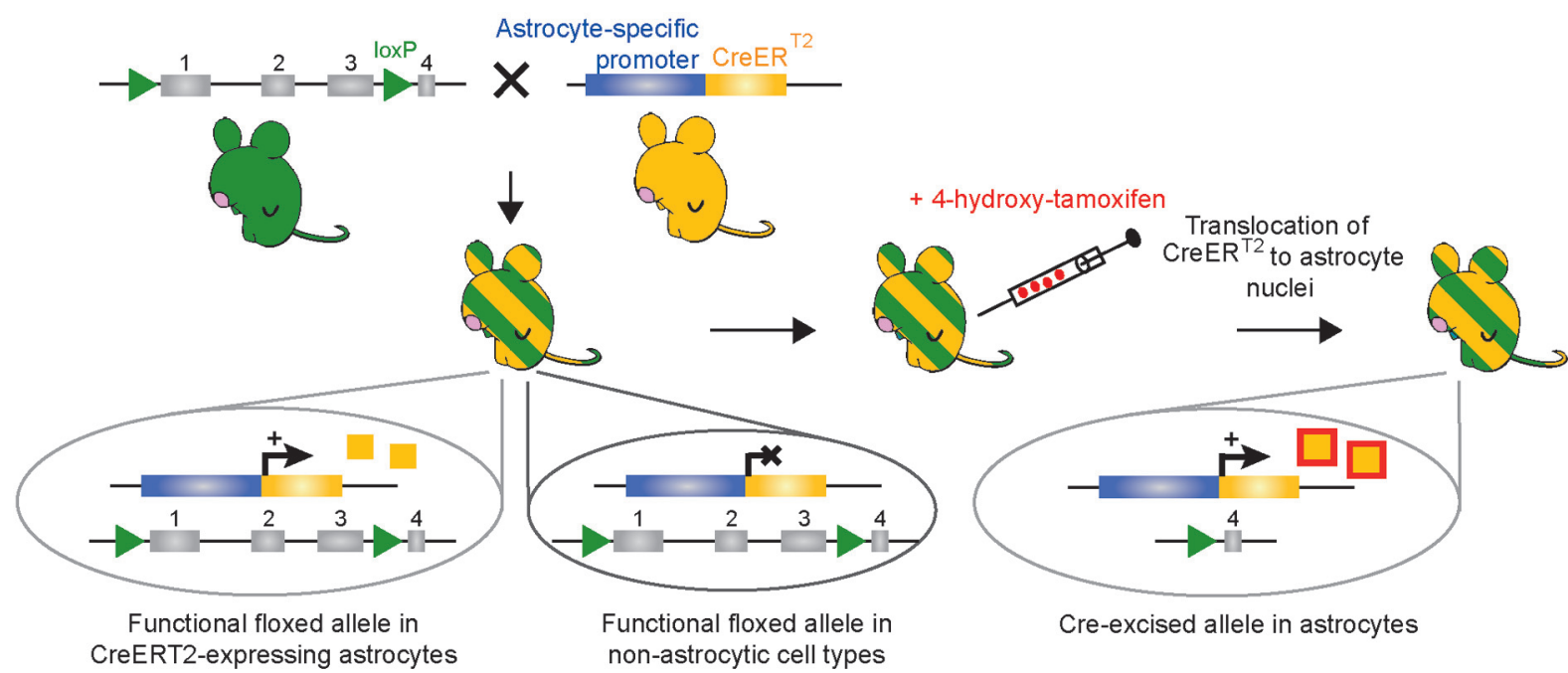

FIGURE 1 | Schematic representation of the main genetic manipulations to make knockout (KO) mice. (A) Conventional strategy for full (constitutive) gene knockout. The targeted gene is inactivated following insertion of an antibiotic (neomycin or neo) resistance gene within, or in place, of one of several essential exons(s) through electroporation of a targeting vector in murine embryonic stem (ES) cells and subsequent homologous

recombination. Totipotent embryonic ES cells with successful recombination will survive neomycin treatment to be selectively chosen and injected in mouse blastocysts. Blastocytes are then transferred to the uterus of pseudopregnant females where they can differentiate into all cell types of a chimeric mouse (red circles). After breeding the chimeric mice, the resulting offspring will derive from the ES cells - as seen with the transmission of coat color (red) - if the introduced ES cells become established into the germline of the chimeric mouse. In the full $\mathrm{KO}$, the gene of interest is knocked out in all cell types (not only astrocytes) of the offspring. (B) Classical Cre-LoxP strategy for conditional gene knockout. The creation of two mouse lines is necessary. First, a floxed mouse line (green) is obtained by homologous

(Continued) 


\section{FIGURE 1 | Continued}

recombination in ES cells. Two LoxP sites are positioned in intronic regions that flank one or several essential exons of the targeted gene. In this mouse line the targeted gene is normally expressed. Second, a Cre mouse line (orange) created by classical transgenesis, following pronuclear injection of the cDNA encoding the Cre-recombinase under the control of an astrocyte-specific promoter. This line gives astrocyte selectivity to the system. Breeding of the floxed mouse with the Cre mouse leads to the generation of a new mouse line (green/orange-striped) in which the floxed exon(s) are excised only in astrocyte-expressing Cre, while the targeted gene remains functional in other cell types. In this case the

Cre-recombinase (orange squares) is constitutively expressed, i.e., inactivation of the targeted gene occurs as soon as the astrocyte-specific promoter driving Cre-recombinase is active. (C) Inducible CreER ${ }^{\mathrm{T} 2}$-LoxP strategy for temporal control of gene knockout. As in (B), a floxed mouse line (green) and a CreER ${ }^{T 2}$ mouse line (yellow) are necessary to obtain a third mouse line (green/yellow-striped) in which the floxed exon(s) are excised only in astrocyte-expressing $\mathrm{CreER}^{\mathrm{T} 2}$. In this mouse line, the CreER ${ }^{T 2}$-recombinase (yellow squares) is expressed in astrocytes but is kept in the cytoplasmic compartment and is inactive. To achieve temporal control of the gene knockout, $\mathrm{CreER}^{\mathrm{T} 2}$ activity (red/yellow squares) is induced by synthetic steroid ligand (tamoxifen or 4-hydroxy-tamoxifen capable of crossing the blood brain barrier) administrated systemically at any chosen time. Binding of steroid to CreER ${ }^{\mathrm{T} 2}$ allows translocation of $\mathrm{CreER}^{\mathrm{T} 2}$ to the nucleus where recombination of floxed genes can occur selectively in astrocytes while the targeted gene remains functional in other cell types.

In light of more recent evidence suggesting that astrogliosis is not a uniform process but rather a multifaceted response with context-dependent reactions (reviewed in Sofroniew, 2009; Sofroniew and Vinters, 2010), the GFAP KO mouse models will continue to be valuable tools in future studies seeking to further unravel the function of GFAP and astrocytes in the variety of human brain challenges or diseases in vivo. These mouse models will assist in understanding the stages when astrocytes are engaged in beneficial or detrimental functions. Furthermore, a number of considerations can be taken into account which may lead to both a re-evaluation of earlier findings using these mice as well as open up new research directions. These include the following: (i) the heterogeneity of astrocyte morphology and physiology (Aley et al., 2006; Emsley and Macklis, 2006; Lee et al., 2006; Matyash and Kettenmann, 2010; Zhang and Barres, 2010; Oberheim et al., 2012; Freeman and Rowitch, 2013; Schreiner et al., 2013); (ii) the variability of GFAP expression levels among this heterogeneous cell population (Bernal and Peterson, 2011; Daniel-Christoph et al., 2013); (iii) the fluctuation of GFAP expression during circadian light-dark cycles, hormonal cycles, developmental, or pathological stages (Hajos, 2008); (iv) the existence of about eight alternatively spliced GFAP isoforms that may execute distinct functions in specific subsets of astrocytes (Middeldorp and Hol, 2011); and (v) the post-translational modification of these different isoforms such as phosphorylation and glycosylation that may influence GFAP assembly into intermediate filaments (Middeldorp and Hol, 2011). Suitable GFAP isoform-specific KO models will be required in future studies to address these issues. One way to investigate the impact of alternative splicing of the GFAP gene in a mouse model would be to selectively delete a single isoform. This can be accomplished by deleting a coding exon from the genome, introducing a stop codon, inactivating the splice sites responsible for generating a specific isoform, or overexpressing a dominant negative version of a certain isoform (Moroy and Heyd, 2007). An alternative way to investigate the impact of alternative GFAP splicing would be to use antisense oligonucleotides to prevent the inclusion of a particular exon in the mature mRNA (Gebski et al., 2003; Dori et al., 2005). Isoform-specific KO mouse models provide a compelling approach to study how alternative splicing of the GFAP gene may contribute to the regulation of pathophysiological CNS processes in vivo.

\section{Role of $I P_{3} R \mathbf{2}$ in normal synaptic transmission and plasticity}

Another global $\mathrm{KO}$ of a gene in astrocytes is the gene encoding the inositol-1,4,5-trisphosphate type 2 receptor $\left(\mathrm{IP}_{3} \mathrm{R} 2\right)$. Two constitutive $\mathrm{IP}_{3} \mathrm{R} 2$-deficient mouse models have been obtained through a variation of the gene targeting strategy. In one, the targeting construct was generated by flanking exon 3 of $\mathrm{IP}_{3} \mathrm{R} 2$ with two LoxP sites and flanking the neo-cassette by FRT sites (Li et al., 2005). In the other, exon 1 of the gene was fused with a LacZ cassette (Futatsugi et al., 2005). Deletion of the $\mathrm{IP}_{3} \mathrm{R} 2$ subtype is a valuable tool in astrocyte research, as it is the only functional $\mathrm{IP}_{3} \mathrm{R}$ subtype expressed by astrocytes and the main mechanism by which astrocytes elevate intracellular $\mathrm{Ca}^{2+}$ levels (Petravicz et al., 2008; Agulhon et al., 2010; Di Castro et al., 2011; Takata etal., 2011). This mouse line has been critical to address the concept of gliotransmission, which stipulates that neuroactive molecules including neurotransmitters (called gliotransmitters) are released from mature passive astrocytes in a neuronally-induced and $\mathrm{Ca}^{2+}$-dependent manner downstream of $\mathrm{G}_{\mathrm{q}}$ protein-coupled receptors $\left(\mathrm{G}_{\mathrm{q}}\right.$ GPCRs) to quickly modulate synaptic transmission and plasticity (illustrated and comprehensively discussed in Agulhon et al., 2008, 2012; Hamilton and Attwell, 2010). Upon $\mathrm{G}_{\mathrm{q}}$ GPCR activation, $\mathrm{IP}_{3}$ is produced intracellularly, leading to astrocytic $\mathrm{IP}_{3} \mathrm{R} 2$ activation and $\mathrm{Ca}^{2+}$ release from the endoplasmic reticulum. Ex vivo and in vivo studies demonstrate that $\mathrm{Ca}^{2+}$ transients in mature passive astrocytes are driven by metabotropic $\mathrm{G}_{\mathrm{q}}$ GPCRs, which can be activated by the spillover of neurotransmitters released from presynaptic terminals (Porter and McCarthy, 1996; Wang et al., 2006). Therefore, astrocytic $\mathrm{G}_{\mathrm{q}}$ GPCRs are considered to be the physiological link between neuronal activity and detectable $\mathrm{Ca}^{2+}$ increases in mature astrocytes. However, it is important to keep in mind that future studies using improved imaging methods may reveal alternate sources of activity-driven $\mathrm{Ca}^{2+}$ transients in astrocytes. For example, new membranetethered genetically encoded $\mathrm{Ca}^{2+}$ indicators have allowed for detection of previously unreported constitutive $\mathrm{Ca}^{2+}$ transients (Shigetomi et al., 2013b; Tong et al., 2013).

The use of the $\mathrm{IP}_{3} \mathrm{R} 2 \mathrm{KO}$ mouse model was done to selectively obliterate the endogenous $\mathrm{G}_{\mathrm{q}} \mathrm{GPCR} / \mathrm{IP}_{3} \mathrm{R} 2$-mediated $\mathrm{Ca}^{2+}$ elevations. The initial studies using this mouse model reported that removing astrocytic $\mathrm{G}_{\mathrm{q}}$ GPCR/IP 3 R2-mediated $\mathrm{Ca}^{2+}$ fluxes did not affect basal and evoked excitatory synaptic transmission (EPSCs), or short- and long-term plasticity (NMDA receptordependent LTP) in the hippocampus ex vivo (Fiacco et al., 2007; Petravicz etal., 2008; Agulhon et al., 2010). The implications of these findings have already been well documented and discussed (Agulhon etal., 2008, 2010, 2012; Petravicz et al., 2008; Fiacco et al., 2009a; Hamilton and Attwell, 2010; Kirchhoff, 2010; Nedergaard and Verkhratsky, 2012). Recently, an ex vivo study 
replicated some of the above-described data by showing that hippocampal NMDA receptor-mediated LTP is normal in $\mathrm{IP}_{3} \mathrm{R} 2 \mathrm{KO}$ mice, supporting the initial findings that the $\mathrm{IP}_{3} \mathrm{R} 2$-mediated internal $\mathrm{Ca}^{2+}$ store pathway is not involved in activity-evoked gliotransmitter release at the hippocampal CA1-CA3 synapses (Shigetomi et al., 2013b). Moreover, the authors of this study discovered a novel mechanism based on transient receptor potential A1 (TRPA1)-mediated transmembrane $\mathrm{Ca}^{2+}$ fluxes, through which astrocytes can modulate LTP. They found that pharmacological blockade or genetic deletion of a recently described TRPA1 channel in astrocytes alters free basal $\mathrm{Ca}^{2+}$ levels, leading to a decrease in $\mathrm{Ca}^{2+}$-dependent constitutive/homeostatic release of D-serine, and thus LTP reduction - in support of a previous study (Henneberger et al., 2010). Such $\mathrm{Ca}^{2+}$ rises are not the type of neuronally-induced astrocyte $\mathrm{Ca}^{2+}$ elevations suggested to drive fast release of gliotransmitters by mature astrocytes. Overall these findings emphasize how different astrocyte $\mathrm{Ca}^{2+}$ sources (i.e., activity-evoked $\mathrm{G}_{\mathrm{q}}$ GPCR/IP 3 R2-dependent $\mathrm{Ca}^{2+}$ elevations vs. constitutive TRPA1-dependent basal $\mathrm{Ca}^{2+}$ dynamics) have distinct effects on LTP (Shigetomi et al., 2013b), and potentially other physiological effects previously attributed to $\mathrm{IP}_{3} \mathrm{R} 2$-driven astrocyte $\mathrm{Ca}^{2+}$ elevations.

Recent studies using $\mathrm{IP}_{3} \mathrm{R} 2 \mathrm{KO}$ mice in vivo reported that hippocampal muscarinic or cortical NMDA receptor-mediated LTP is diminished or abolished, suggesting a role for $\mathrm{IP}_{3} \mathrm{R} 2$-driven $\mathrm{Ca}^{2+}$ elevations in synaptic plasticity (Takata et al., 2011; Navarrete et al., 2012). Two exciting new reports are providing a potential explanation for the differences observed between the early and later studies using the $\mathrm{IP}_{3} \mathrm{R} 2 \mathrm{KO}$. By using a broad range of $\mathrm{G}_{\mathrm{q}}$ GPCR antagonists, Wang and coauthors excluded the occurrence of gliotransmission both ex vivo and in vivo (Wang et al., $2012 \mathrm{a}, \mathrm{b})$, consistent with the prior ex vivo studies using the $\mathrm{IP}_{3} \mathrm{R} 2$ KO mice. Rather, they identified a mechanism by which astrocytic $\mathrm{G}_{\mathrm{q}} \mathrm{GPCR} / \mathrm{IP}_{3} \mathrm{R} 2$-mediated $\mathrm{Ca}^{2+}$ elevations stimulate the $\mathrm{Na}^{+}, \mathrm{K}^{+}$-ATPase, leading to a transient $\mathrm{K}^{+}$uptake by astrocytes, a decrease in the extracellular $\mathrm{K}^{+}$concentration, and a subsequent modulation of excitatory postsynaptic currents. This modulation of synaptic transmission was not observed in the $\mathrm{IP}_{3} \mathrm{R} 2 \mathrm{KO}$ mice, implying that astrocyte $\mathrm{G}_{\mathrm{q}} \mathrm{GPCR} / \mathrm{IP}_{3} \mathrm{R} 2 / \mathrm{Ca}^{2+}$-induced decrease of extracellular $\mathrm{K}^{+}$concentration endows astrocytes with a simple and powerful mechanism for rapid modulation of neuronal activity (Wang et al., 2012a,b). Modulation of $\mathrm{K}^{+}$uptake by astrocytic $\mathrm{G}_{\mathrm{q}}$ GPCRs was also observed ex vivo (Devaraju et al., 2013; Wang et al., 2013). Rapid modification of $\mathrm{K}^{+}$uptake provides a mechanism which may be responsible for effects on neuronal activity that hitherto have been ascribed to gliotransmission. Nevertheless, synaptic properties are variable within the nervous system, and astrocytes represent a genetically and functionally heterogeneous group of cells (Zhang and Barres, 2010; Oberheim et al., 2012); these cells are likely to exhibit different functions in different areas of the CNS or even within the same area. Therefore, the different effects of knocking out $\mathrm{IP}_{3} \mathrm{R} 2$ on neuronal activity support the need to consider heterogeneity of astrocytes between different brain regions when comparing data across studies. Further investigation is necessary to determine the mechanisms involved in activity-induced astrocytic $\mathrm{G}_{\mathrm{q}} \mathrm{GPCR} / \mathrm{IP}_{3} \mathrm{R}_{2} / \mathrm{Ca}^{2+}$-mediated modulation of neuronal excitability and LTP in vivo.
In our view, a fundamental and still open question remains to be answered in order to address this issue thoroughly: do neurons express $\mathrm{IP}_{3} \mathrm{R} 2$ ? If so, does this neuronal receptor subtype play a role in specific types of synaptic transmission and plasticity? Fully deleting $\mathrm{IP}_{3} \mathrm{R} 2$ abolishes spontaneous and activity- or agonist-dependent $\mathrm{G}_{\mathrm{q}}$ GPCR/IP 3 R2-mediated $\mathrm{Ca}^{2+}$ increases in astrocytes but leaves intact neuronal $\mathrm{Ca}^{2+}$ signaling (Petravicz et al., 2008; Di Castro et al., 2011; Takata et al., 2011; Chen etal., 2012; Navarrete etal., 2012; Wang etal., 2012a,b). However, caution should be exercised in the interpretation of the positive physiological data using this mouse model. Indeed, past immunohistochemical studies aimed at identifying the expression of $\mathrm{IP}_{3} \mathrm{R} 2$ in neurons were inconclusive (Sharp et al., 1999; Holtzclaw et al., 2002; Hertle and Yeckel, 2007), and most recent antibodies against this $\mathrm{IP}_{3} \mathrm{R}$ subtype are of poor quality (Takata et al., 2011; Chen et al., 2012). Additionally, functionally testing whether neurons display $\mathrm{IP}_{3} \mathrm{R} 2$-mediated $\mathrm{Ca}^{2+}$ signaling would require the use of double $\mathrm{KOs}$ for the two other $\mathrm{IP}_{3} \mathrm{R}$ subtypes $\left(\mathrm{IP}_{3} \mathrm{R} 1\right.$ and $\left.\mathrm{IP}_{3} \mathrm{R} 3\right)$, which is complicated because most of the $\mathrm{IP}_{3} \mathrm{R} 1$-deficient mice die in utero (Matsumoto et al., 1996). We are then left with the possibility that some neurons, which also have heterogeneous subtypes throughout the brain, may express $\mathrm{IP}_{3} \mathrm{R} 2$ in addition to $\mathrm{IP}_{3} \mathrm{R} 1$ and/or $\mathrm{IP}_{3} \mathrm{R} 3$. Such a hypothesis, if validated, could help address some of the discrepancies between positive and negative findings using the $\mathrm{IP}_{3} \mathrm{R} 2 \mathrm{KO}$ mice. The use of inducible conditional $\mathrm{IP}_{3} \mathrm{R} 2 \mathrm{KO}$ mice to selectively knock out $\mathrm{IP}_{3} \mathrm{R} 2$ in neurons vs. astrocytes in adult mice appears to be the next obvious step to help differentiate between neuronal vs. astrocytic $\mathrm{G}_{\mathrm{q}}$ GPCR effects on neuronal excitability and LTP in vivo. Finally, the currently available and future inducible $\mathrm{IP}_{3} \mathrm{R} 2$ KO mouse models may help provide insight into brain pathology; recent studies suggest that abnormal (increased) astrocytic $\mathrm{Ca}^{2+}$ dynamics are linked to the symptoms of Alzheimer's disease (Takano et al., 2007; Kuchibhotla et al., 2009; Grolla et al., 2013), suggesting that controlling astrocytic $\mathrm{Ca}^{2+}$ homeostasis might be a potential form of therapy for neurodegenerative disease.

\section{CONDITIONAL AND INDUCIBLE CONDITIONAL KNOCKOUT MOUSE MODELS}

The complete knock out of genes in mice has allowed researchers to investigate the role of specific genes in vivo. When a gene is selectively expressed in a specific cell type and/or tissue, a constitutive KO is thus cell-specific and/or tissue-specific. However, it is rare that genes are expressed by a single cell type. In such instances, the phenotypes of $\mathrm{KO}$ mice can be very complex to interpret and it is not uncommon for a $\mathrm{KO}$ mouse to display embryonic lethality (Matsumoto et al., 1996), show no phenotype at all, or affect other gene products (Iacobas et al., 2004). To overcome these obstacles, genes have been knocked out in a cell-specific manner with the use of Cre recombinase/LoxP technology. Such gene KOs are referred to as conditional gene KOs (cKO; Figure 1B). The site-specific recombination system of the P1 bacteriophage using Cre and LoxP-flanked genes is well documented (Sternberg and Hamilton, 1981), although it was only much later that it was used in mouse lines to induce cell-specific gene cKOs in non-nervous and/or nervous tissues (Gu et al., 1994; 
Morozov et al., 2003). In order to accomplish this, two mouse lines are required: one that has been genetically engineered to express the Cre site-specific DNA recombinase of bacteriophage P1 under a cell-specific promoter (transgenic mice; Figure 2A), and a second that has been made via homologous recombination in ES cells expressing the 34-base-pair LoxP site (recognition site for Cre recombinase) flanking the gene of interest or one or more exons of this gene. When these two mouse lines are crossed, the gene or exons of interest are excised to obtain the desired cKO mouse line (reviewed in Sauer, 1998; Figure 1B). While cKO mice are very valuable tools, their use has been limited in the astrocyte field because the promoters that are known to be astrocyte specific in the adult are also expressed in progenitor cells of the developing brain. As a consequence, not only astrocytes, but also a large percentage of neurons and oligodendrocytes, exhibit recombination when using astrocyte-specific promoters to drive the expression of Cre recombinase (Gotz et al., 2002; Malatesta et al., 2003; Anthony et al., 2004; Merkle et al., 2004; Casper and McCarthy, 2006). This limitation prompted investigators in the field to develop transgenic mice that enable inducible cell-specific gene KOs in order to recombine astrocytic genes postdevelopmentally (referred to as inducible cKO mice; Figure $\mathbf{1 C}$ ). To this end, mice have been developed which express Cre recombinase fused to a mutated form of the human estrogen receptor $\left(\mathrm{ER}^{\mathrm{T} 2}\right)$ that restricts the fusion protein to the cytoplasm unless exposed to the estrogen analog tamoxifen (or 4-hydroxy-tamoxifen; Feil et al., 1997). This form of the Cre recombinase, called $\mathrm{CreER}^{\mathrm{T} 2}$, enters the nucleus to cause cell-specific recombination only when tamoxifen is given to mice

\section{A Conditional transgenic}

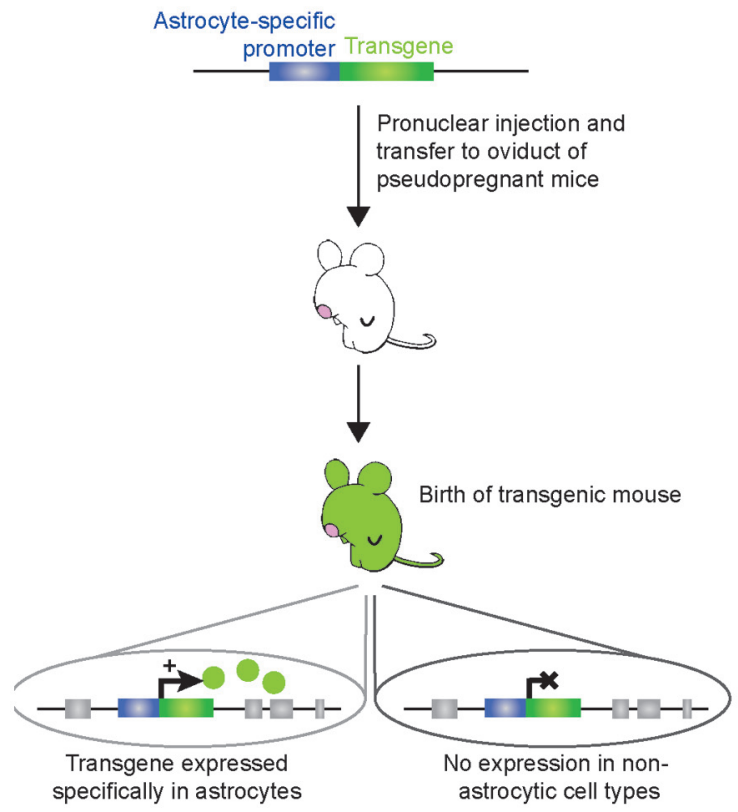

FIGURE 2 | Schematic representation of the genetic modification systems to make astrocyte-specific transgenic mice. (A) Conventional strategy for conditional expression of a transgene selectively in astrocytes. A transgene of interest is placed under the control of an astrocyte-specific promoter; this cDNA construct is purified and microinjected into the male pronucleus of fertilized murine eggs. Several copies of the DNA will be randomly inserted in the mouse genome. Then, the eggs are transferred to the oviduct of pseudopregnant females. The resulting offspring (green) deriving from the eggs will display constitutive transgene expression selectively in astrocytes as soon as the astrocyte-specific promoter is active, while it will not be expressed in other cell types. (B) Tet-Off strategy for inducible and temporal control of transgene expression selectively in astrocytes. The TeT-Off system has been used more frequently than the Tet-On system, and is based on the tetracycline (tet) bacterial resistance gene operon. The creation of two transgenic lines is required. The first transgenic line (orange) contains the tTA under the control of an astrocyte-specific

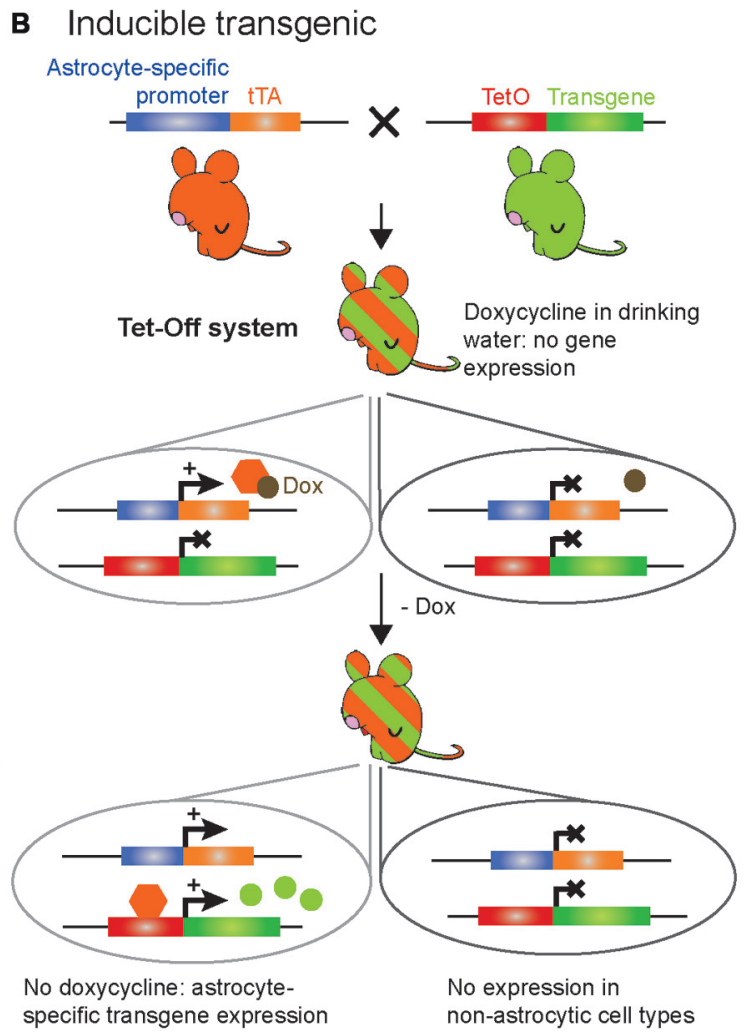

promoter: this line provides astrocyte selectivity to the system. The second transgenic line (green) contains the transgene of interest under the control of the tet operon (TetO) DNA-binding element fused to a minimal promoter from cytomegalovirus. The TetO promoter element can be activated upon binding of the tetracycline transactivator (tTA) to drive ubiquitous expression. When a tetracycline derivative, such as doxycycline, is given to the bigenic mice (green/orange-striped - obtained from breeding the tTA line with the TetO line) in the drinking water, doxycycline binds to tTA to prevent its interaction with the TetO minimal promoter and thereby turn off transgene expression selectively in astrocytes. Removing doxycycline from the drinking water of the bigenic mice leads to binding of tTA to the TetO minimal promoter and transcription of the transgene of interest within a week. This allows desired temporal expression of the transgene selectively in astrocytes while it is not expressed in other cell types. Additionally, this system allows testing whether potential physiological or behavioral effects of the transgene are reversible by putting the bigenic mice back on doxycycline. 
(Hayashi and McMahon, 2002). Thus, genetically engineered mice expressing CreER ${ }^{\mathrm{T} 2}$ under the control of an astrocyte-specific promoter (e.g., GFAP, glutamate transporter GLAST, Aldh1l1 or Cx43) allows study of the effect of gene deletion specifically in astrocytes if tamoxifen is given to mice at later development stages (Eckardt et al., 2004; Hirrlinger et al., 2006; Mori et al., 2006; Casper et al., 2007; Figure 1C). One limitation of the $\mathrm{CreER}^{\mathrm{T} 2}$ inducible system and inducible systems in general is that recombination efficiency may be low and therefore the phenotypes generated may be more subtle, as has been reported for $\mathrm{Cx} 43$ compared to floxed reporter genes (Casper et al., 2007).

\section{Role of $C B_{1} R$ in working memory}

Multiple inducible $\mathrm{cKO}$ mice have been recently developed to study astrocytic function in vivo. One example is a tamoxifeninducible $\mathrm{cKO}$ mouse specifically lacking cannabinoid type-1 receptor $\left(\mathrm{CB}_{1} \mathrm{R}\right)$ expression in astrocytes (Han et al., 2012). A mouse line carrying a LoxP-flanked $\mathrm{CB}_{1} \mathrm{R}$ (Marsicano et al., 2003) was crossed with a line expressing $\mathrm{CreER}^{\mathrm{T} 2}$ under the control of the human GFAP promoter (Hirrlinger et al., 2006). The resulting new line of mice (GFAP-CB ${ }_{1} \mathrm{R}-\mathrm{KO}$ ) has been used to investigate the mechanisms underlying impairment of working memory, which is one of the most important deleterious effects of marijuana intoxication in humans (Ranganathan and D'Souza, 2006) and animals (Lichtman and Martin, 1996; Wise et al., 2009). Understanding the side-effects associated with the use of marijuana has important clinical implications because the derivatives of marijuana or synthetic cannabinoids represent promising therapeutic molecules for several human conditions, including pain, nausea, seizures, ischemia, cerebral trauma, and tumors (Lemberger, 1980; Carlini, 2004; Hall et al., 2005). The endocannabinoid system has recently emerged as an important neuromodulatory system, and the $\mathrm{CB}_{1} \mathrm{R}$ (GPCR predominantly coupling to $G_{i}$ proteins) is highly abundant in the CNS (Herkenham et al., 1990; Matsuda et al., 1990). In particular, the $\mathrm{CB}_{1} \mathrm{R}$ is expressed in glutamatergic and GABAergic neurons (Herkenham et al., 1990; Kawamura et al., 2006) as well as in astrocytes (Navarrete and Araque, 2008; Han et al., 2012) of the hippocampal CA1 area, an area that contributes to spatial working memory (SWM). Because past studies have established that $\mathrm{CB}_{1}$ Rs mediate retrograde inhibition of neurotransmitter release, control neuronal excitability, and regulate short- and long-term plasticity (Di Marzo et al., 1994; Kreitzer and Regehr, 2001; Alger, 2002; Wilson and Nicoll, 2002; Freund et al., 2003; Chevaleyre et al., 2006; Maldonado et al., 2006; Heifets and Castillo, 2009; Kano et al., 2009), research on the function of $\mathrm{CB}_{1} \mathrm{R}$ signaling in pain (Kato et al., 2012), aversive memory (Marsicano et al., 2002), epilepsy (Monory et al., 2006), food intake (Bellocchio et al., 2010), analgesia (Zimmer et al., 1999), or development (Jin et al., 2004) has focused mainly on neuronal $\mathrm{CB}_{1}$ Rs using neuronal-specific $\mathrm{CB}_{1} \mathrm{R}$ KO mouse models. However, Han et al. (2012) report an unappreciated, yet major, role of astrocytic $\mathrm{CB}_{1}$ Rs in SWM. Their results show that acute cannabinoid exposure in vivo elicits a previously unreported form of LTD at CA3-CA1 hippocampal synapses, which is associated with an impairment of SWM; both effects are abolished in tamoxifen-treated GFAP-CB ${ }_{1} \mathrm{R}-\mathrm{KO}$, but conserved in mice lacking $\mathrm{CB}_{1} \mathrm{R}$ in glutamatergic or GABAergic neurons (Han et al., 2012). These findings strongly suggest that astrocytic $\mathrm{CB}_{1} \mathrm{R}$ is a primary mediator of cannabinoid-induced LTD. Based on further in vivo pharmacological studies, the authors speculated that their findings are consistent with the possibility that acute exogenous cannabinoid exposure leads to glutamate release from astrocytes, which in turn could activate extrasynaptic NR2B-containing NMDA receptors to trigger AMPA receptor internalization at CA3-CA1 synapses. These events could eventually induce cannabinoid-mediated LTD at these synapses, altering hippocampal SWM. However, several points should to be kept in mind when considering this interpretation of the data, which might imply a substantially more complex mechanism at the CA1-CA3 synapses: (i) the apparent mechanistic discrepancy between this in vivo cannabinoid-induced LTD and previous ex vivo "gliotransmission" studies suggesting that astrocytic $\mathrm{CB}_{1} \mathrm{R}$ mediated $\mathrm{Ca}^{2+}$ increases trigger the release of glutamate to activate pre-synaptic mGluRs that leads to glutamate presynaptic release and subsequent potentiation of postsynaptic NMDA receptormediated currents (Navarrete and Araque, 2008, 2010); (ii) the current debate as to whether astrocytes actually release glutamate in a GPCR/Ca ${ }^{2+}$-dependent manner in vivo (Wang et al., 2012a compared to Navarrete et al., 2012); (iii) the emerging evidence that astrocyte GPCR/Ca ${ }^{2+}$-dependent release of glutamate occurs in the early steps of inflammatory processes rather than during normal physiology (Agulhon et al., 2012; Pascual et al., 2012); (iv) the recent findings suggesting that astrocytic GPCR/Ca ${ }^{2+}$ triggers an increase of $\mathrm{K}^{+}$uptake (Wang et al., 2012a,b; Devaraju et al., 2013); and (v) a past study reporting that LTD is modulated by astrocytic $\mathrm{K}^{+}$uptake (Janigro et al., 1997). Further investigation should help determine whether cannabinoid-induced LTD is due to an increase of extracellular glutamate, a decrease of extracellular $\mathrm{K}^{+}$, a combination of both, or some other mechanism.

\section{Role of DRD2 in neuroinflammation}

Astrocytes become reactive in nearly all brain pathologies, and play important roles in neuroinflammation, a common feature of the aging brain and most neurological disorders and neurodegenerative diseases (Sofroniew, 2009; Sofroniew and Vinters, 2010). Changes in reactive astrocytes include upregulation of GFAP expression (Pekny and Nilsson, 2005), secretion of inflammatory mediators from astrocytes (Lucas et al., 2006; Peng etal., 2006; Farina etal., 2007; Brambilla etal., 2009; Steele and Robinson, 2012), and altered expression of astrocytic GPCRs (Aronica etal., 2003; Hamby etal., 2012). One such GPCR is the dopamine D2 receptor (DRD2) that couples to $G_{i}$ (Missale et al., 1998) and is expressed not only in neurons, but also in astrocytes (Bal et al., 1994; Khan et al., 2001; Luo et al., 2009). Downregulation of DRD2 expression has been reported in the brain of the elderly (Kaasinen et al., 2000), suggesting that astrocytic DRD2 signaling may be involved in neuroinflammation that occurs in the CNS during aging and disease. A recent study has investigated this question using both astrocytespecific cKO and tamoxifen-inducible cKO mouse models (Shao et al., 2013). Several complementary methodological approaches have been used, including immunohistochemistry, biochemistry, and molecular biology to show that DRD2-deficient astrocytes show robust GFAP upregulation in the substantia nigra of aged 
mice. Moreover, DRD2-deficient astrocytes were found to produce more proinflammatory mediators than their wild-type counterparts, suggesting that astrocytic DRD2 is a key negative regulator of neuroinflammation. To identify the downstream effectors of DRD2 that might be involved in the regulation of inflammatory mediator production, microarray analysis was carried out and showed a pronounced decrease of the small heat-shock protein $\alpha \mathrm{B}$-crystallin (CRYAB) in DRD2-deficient astrocytes, a protein known to display anti-inflammatory and neuroprotective activities (Ousman et al., 2007; Bhat and Steinman, 2009). These findings suggest that activation of astrocytic DRD2 controls CRYAB expression to suppress inflammatory responses in astrocytes and thus contribute to the maintenance of the immune state balance under normal conditions (Shao et al., 2013). The implications of these findings are profound in age-related diseases, where a decrease of DRD2 signaling in astrocytes may lead to an abnormal increase of proinflammatory mediator release, and underlie the progression of cognitive and motor function impairments. Therefore, the astrocyte DRD2 signaling pathway could be a potential target for therapy of several neurological, neuroinflammatory, and neurodegenerative disorders, in which production of inflammatory mediators is a common element (Lucas et al., 2006).

It is interesting, however, to note that activation of another $\mathrm{G}_{\mathrm{i}}$ GPCR, called CXCR4 in cultured cortical astrocytes has previously been reported to increase release of the proinflammatory cytokine tumor necrosis factor $\alpha$ (TNF $\alpha$; Bezzi et al., 2001), and not to negatively control the release of proinflammatory molecules as reported by Shao etal. (2013). Several obvious possibilities may explain these differences: (i) astrocytic $G_{i}$ signaling triggers different cellular mechanisms depending on whether the studies are performed in vivo vs. ex vivo cultures; (ii) astrocytic $\mathrm{G}_{\mathrm{i}}$ signaling leads to distinct responses depending on the area of the brain (e.g., substantia nigra vs. cortex); or (iii) astrocytic $\mathrm{G}_{\mathrm{i}}$ GPCRs are involved in different functions depending on the developmental stage (mature vs. immature astrocytes). Additionally, another possibility that has not been addressed thoroughly in the field when investigating the role of astrocyte signaling in general is that different astrocytic $G_{i}$ GPCRs may activate distinct signaling pathways even though they are known to couple to $G_{i}$ proteins. In other words, depending on the endogenous or synthetic agonist used to active a specific $G_{i}$ GPCR, this receptor may show a different bias toward other $G$ proteins over $G_{i}$ or different functional selectivity for $\beta$-arrestin recruitment over $\mathrm{G}_{\mathrm{i}}$ activation (Allen et al., 2011; Zidar, 2011; Audet et al., 2012; Blattermann etal., 2012; Hiller etal., 2013). The depth of the complexity of GPCR signaling is now becoming familiar territory to receptor biologists, yet the application of this knowledge to the astrocyte field remains extremely limited. Therefore, findings relative to astrocytic GPCR signaling (coupling to $G_{q}, G_{i}$, or $\mathrm{G}_{\mathrm{s}}$ proteins) in physiology and pathology likely reflect the complex interactions of multiple signaling pathways and provides an explanation for seemingly contradictory observations. Examples of this have already been observed relative to astrocyte $\mathrm{Ca}^{2+}$ signaling which is traditionally ascribed to $\mathrm{G}_{\mathrm{q}}$ GPCR signaling pathways, yet astrocytic $\mathrm{G}_{\mathrm{i}}$-coupled $\mathrm{GABA}_{B}$ and $\mathrm{CB}_{1}$ Rs also have been reported to evoke $\mathrm{Ca}^{2+}$ elevations in astrocytes
(Serrano et al., 2006; Navarrete and Araque, 2008). Future studies using biased ligands in combination with astrocyte-specific cKOs of specific $\mathrm{G}$ proteins or $\beta$-arrestins is one approach to elucidate the role of astrocyte signaling molecules in brain function and dysfunction.

\section{STUDYING ASTROCYTE FUNCTION THROUGH GENE EXPRESSION OR CELL-SPECIFIC RESCUE OF GLOBAL GENE KNOCKOUT}

As methods for generating full or inducible conditional gene $\mathrm{KO}$ have been useful in deciphering some of the astrocyte gene functions in vivo, constitutive, inducible, and/or reversible regulation of gene expression represent other powerful approaches for understanding astrocyte function. To this end, four molecular approaches can be used: (i) expression of a genetically modified gene (transgene); (ii) reversible regulation of an endogenous gene; (iii) viral transduction of genes; or (iv) in utero gene electroporation (IUE).

\section{TRANSGENE EXPRESSION}

Conventional (Figure 2A) and inducible (Figure 2B) transgenesis allowing for astrocyte-specific expression of transgenes, constitutively or at specific times, have been used in the field. These approaches employ a small transcriptional unit derived from astrocyte-specific promoters. Of importance for the topic of this review, mapping of the transcriptional regulatory elements of the GFAP promoter has been critical to develop regulatory units (promoters) of small size to direct transgene expression in the majority of astrocytes in vivo without significant expression in other cell types in the brain (Masood et al., 1993; Brenner, 1994; Brenner et al., 1994). Other astrocyte-specific promoters have also been used successfully to drive transgene expression in astrocytes, such as $\mathrm{Cx} 30, \mathrm{Cx} 43, \mathrm{~S} 100 \mathrm{~b}$, Aldh1l1, or GLAST promoters (reviewed in Pfrieger and Slezak, 2012). The DNA construct containing a promoter fused to the transgene of interest is microinjected into the male pronucleus of fertilized eggs for random insertion in the mouse genome, followed by transfer of the fertilized eggs to the oviduct of pseudopregnant recipient females (Cho et al., 2009; Figure 2A). The resulting pups are identified as transgenic by polymerase chain reaction and checked for astrocyte-specific transgene expression. This constitutive gain-offunction approach however does not provide temporal control of the transgene expression, which can be problematic when studying the function of a transgene during developmental stages as mentioned above (Gotz et al., 2002; Malatesta et al., 2003; Anthony etal., 2004; Merkle etal., 2004; Casper and McCarthy, 2006). To overcome this limitation, inducible transgenic mouse models have been developed. The most commonly used method to temporally control gene expression in mouse models is based on the tet-operon/repressor and the estrogen (tetracycline) receptor ligand-binding domain (Gossen and Bujard, 1992; Baron and Bujard, 2000; Mansuy and Bujard, 2000; Saunders, 2011; Figure 2B). This system is bi-transgenic, which means that it involves the mating of two different transgenic mouse lines in order to produce a new tetracycline-regulated transgenic mouse line designed to activate the expression of a transgene in a specific cell type at a specific time point. The first line contains an 
astrocyte-specific promoter driving the expression of the tetracycline (tet) transactivator (tTA). The second line carries the transgene of interest driven by the tet operon (TetO) DNA-binding element fused to a minimal promoter from cytomegalovirus. In this system, bigenic mice are maintained on tetracycline (doxycycline) to block transgene expression. When doxycycline is removed at a given time, tTA then binds to the TetO minimal promoter leading to targeted expression of the transgene of interest (Figure 2B).

\section{Role of astrocytic $G_{q}$ GPCR signaling in physiology and behavior}

One important limitation in addressing the role of astrocytic GPCR signaling in neurophysiology has been the inability to pharmacologically activate astrocytic GPCRs in a cell type-specific manner. Indeed, astrocytes in vivo express members of most of the different families of GPCRs linked to the diverse array of intracellular signaling cascades (Porter and McCarthy, 1997) that are also known to be expressed by neurons. Therefore, the use of pharmacological approaches consisting of agonist application ex vivo or in vivo does not allow cell-specific GPCR activation. Therefore, interpretation of the findings is made difficult by direct activation of neuronal (but also other cell type) receptors by the applied agonist in addition to the intended astrocytic targets. As a consequence, it has been difficult to determine the effect of selectively stimulating astrocytic $\mathrm{G}_{\mathrm{q}}$ GPCR-mediated $\mathrm{Ca}^{2+}$ signaling cascades on physiological processes such as synaptic transmission and plasticity. This complication has led investigators to consider previous reports of gliotransmission with caution.

Thus, advances in this field depend upon the development of novel tools to better address the physiological relevance of astrocytic $\mathrm{G}_{\mathrm{q}}$ GPCR $\mathrm{Ca}^{2+}$ signaling. In order to overcome some of the limitations associated with traditional pharmacological approaches, two novel transgenic mouse models were developed (Fiacco et al., 2007; Agulhon et al., 2013). In the first model, a novel $G_{q}$ GPCR is expressed selectively in astrocytes that is not expressed by other cell types in the brain, is not activated by endogenous ligands released in brain, and whose ligand, the peptide FMRF, does not activate endogenous brain $\mathrm{G}_{\mathrm{q}}$ GPCRs (Fiacco et al., 2007). The novel receptor, the so-called Mas-related gene A1 (MrgA1), is a member of a family of GPCRs normally expressed in specific subsets of nociceptive sensory neurons in the spinal cord (Dong etal., 2001), but is not found in the brain. The MrgA1 receptor is targeted to astrocytes using the inducible Tet-Off system (Figure 2B). In one transgenic mouse line the green fluorescent protein (GFP)-tagged MrgA1 receptor is transcribed from the TetO promoter. When crossed with a second transgenic line in which tTA is targeted to astrocytes using the human GFAP promoter, a bigenic line (referred to as the MrgA1 mice) is obtained, in which MgrA1-GFP is selectively expressed in the vast majority of astrocytes in the absence of doxycycline (Fiacco et al., 2007). Several studies using this novel transgenic MrgA1 mouse model have shown that increasing astrocytic MrgA1-mediated $\mathrm{Ca}^{2+}$ fluxes does not lead to gliotransmission ex vivo and in vivo, suggesting that astrocytes do not release gliotransmitters in a $\mathrm{G}_{\mathrm{q}} \mathrm{GPCR} / \mathrm{Ca}^{2+}$-dependent manner (Fiacco et al., 2007; Agulhon et al., 2010; Wang et al., 2012a,b). Rather, it has been reported that astrocytic MrgA1R-mediated
$\mathrm{Ca}^{2+}$ elevations potentiate astrocyte glutamate and $\mathrm{K}^{+}$uptake (Wang et al., 2012a,b, 2013; Devaraju et al., 2013), suggesting that the mechanisms by which agonist-induced astrocyte $G_{q}$ GPCR activation modulates neuronal activity may be different than previously thought, in agreement with previous and most recent findings (Fiacco et al., 2007; Agulhon et al., 2010; Wang et al., 2013). It is important to bear in mind that agonist-evoked stimulation of $\mathrm{G}_{\mathrm{q}}$ GPCRs, including MrgA1Rs, generates $\mathrm{Ca}^{2+}$ elevations that may not recapitulate some endogenous $\mathrm{Ca}^{2+}$ elevations in astrocytes which often remain confined to fine processes. One strategy in future studies could be to employ a caged version of FMRF to locally stimulate astrocyte $\mathrm{Ca}^{2+}$ elevations by activation of a $\mathrm{G}_{\mathrm{q}}$ signaling pathway, which may more closely resemble the subset of microdomain astrocytic $\mathrm{Ca}^{2+}$ elevations which have been observed in astrocytes in vivo.

More recently, another transgenic mouse line has been developed in order to facilitate investigation of the role of astrocytic $\mathrm{G}_{\mathrm{q}}$ GPCR signaling in vivo (Agulhon et al., 2013). One of the limitations of the MrgA1 mice is that the MrgA1 FMRF ligand does not cross the BBB, making in vivo studies more invasive as surgeries would be required in order to infuse FMRF into the brain of freely moving mice. Additionally, endogenous MrgA1 is expressed in sensory nerve terminals, preventing the use of MrgA1 mice to study spinal cord astrocytes (as FMRF may diffuse and activate endogenous MrgA1 in nociceptive sensory neurons). To overcome some of these obstacles, a new GFAP-hM3Dq mouse line was created (Agulhon et al., 2013). The innovation of this mouse line is based on the use of a novel genetically engineered $G_{q}$ GPCR (called hM3Dq) that does not respond to endogenous ligands, but instead responds to an inert synthetic ligand (clozapine- $N$ oxide, $\mathrm{CNO}$ ) that crosses the $\mathrm{BBB}$ and activates signaling cascades in a similar fashion as endogenous $\mathrm{G}_{\mathrm{q}}$ GPCRs (Armbruster et al., 2007). Such new chemogenetic technology (called designer receptors exclusively activated by a designer drug, or DREADD) has recently led to several important discoveries in neuronal function (e.g., Alexander etal., 2009; Ferguson et al., 2011; Atasoy et al., 2012; Garner etal., 2012), and is now being applied to astrocytes for the first time (Agulhon et al., 2013). This mouse line was made through conventional transgenesis using a construct containing the human GFAP promoter driving the expression of hM3Dq (Figure 2A). Inducible and reversible expression of the transgene is not a constraint when using the DREADD technology, as hM3Dq can be activated postdevelopmentally through intraperitoneal CNO injection. Immunohistochemical screening in adult mice indicates that expression of $\mathrm{hM} 3 \mathrm{Dq}$ is restricted to astrocytes within the CNS, and in non-myelinating Schwann cells of sympathetic, sensory, and sciatic nerves, as well as satellite cells in sympathethic, parasympathetic, and sensory ganglia within the PNS. Such expression is expected for a GFAP-driven transgene and allows CNO-induced global stimulation in $\mathrm{GFAP}^{+}$ glial cells within the CNS and PNS. This provides a powerful approach, as it can reveal most of the physiological and behavioral phenotypes mediated by $\mathrm{GFAP}^{+}$glial cell $\mathrm{G}_{\mathrm{q}}$ GPCR signaling. Acute CNO intraperitoneal injections of GFAP-hM3Dq mice resulted in previously unreported and long-lasting (minutes to hours) modulation of autonomic nervous system (ANS) function, including increased heart rate, blood pressure, and saliva 
formation, as well as decreased body temperature. Furthermore, changes in activity-related behavior and motor coordination were observed in CNO-treated GFAP-hM3Dq mice. To address whether ANS and activity-related effects were due to $\mathrm{Ca}^{2+}$ or other signaling pathways downstream of $\mathrm{G}_{\mathrm{q}}$ GPCR activation, the GFAP-hM3Dq mice were crossed with $\mathrm{IP}_{3} \mathrm{R} 2 \mathrm{KO}$ mice in order to generate GFAP-hM3Dq mice in which $\mathrm{IP}_{3} \mathrm{R} 2$-dependent $\mathrm{Ca}^{2+}$ increases were abolished. Interestingly, CNO-treated GFAP$\mathrm{hM} 3 \mathrm{Dq} / \mathrm{IP}_{3} \mathrm{R} 2$-deficient mice exhibited similar autonomic and motor modulation as CNO-treated GFAP-hM3Dq mice. These findings suggest that $\mathrm{CNO}$-induced phenotypes are not dependent on $\mathrm{IP}_{3} \mathrm{R} 2$-dependent $\mathrm{Ca}^{2+}$ increases. Thus, other (non-Ca ${ }^{2+}$ ) signaling molecules activated by $\mathrm{G}_{\mathrm{q}}$ GPCRs in $\mathrm{GFAP}^{+}$glial cells may be important contributors to the functional effects of $\mathrm{CNO}$. Collectively, these findings open new avenues into investigation of $\mathrm{GFAP}^{+}$glial cell (astrocyte, non-myelinating Schwann cell, satellite cell) function in animal physiology. Further studies employing local CNO infusion into specific regions of the CNS or PNS, and specific blockers of $\mathrm{G}_{\mathrm{q}}$ GPCR signaling molecules (e.g., protein kinase $\mathrm{C}$ or $\beta \gamma$-dependent activation of signaling cascades), will help dissect out the areas of the nervous system and the signaling pathways that are responsible for each of the CNO-induced phenotypes. Viral transduction of hM3Dq in wild-type mice is also a potential strategy to help determine what areas of the CNS vs. PNS are involved in the effects observed in CNO-treated GFAP-hM3Dq mice. Finally, when specific markers of different subpopulations of CNS astrocytes become available, it will be possible to use new promoters to create transgenic mice expressing hM3Dq in distinct subsets of astrocytes. This will allow determination of whether a specific subset of astrocytes is responsible for all of the phenotypes observed in CNO-treated GFAP-hM3Dq mice, or whether different subsets of astrocytes are responsible for distinct phenotypes. Clearly, there is much to be learned with regard to the role of astrocytes, and more generally of $\mathrm{GFAP}^{+}$glial cells, in complex physiology and behavior. Collectively, the findings of this study point to astrocytes as potential therapeutic targets for some ANS or motor dysfunctions.

\section{CELL-SPECIFIC RESCUE OF A GENE KNOCKOUT}

Another powerful molecular approach is to constitutively knock out a particular gene product and then rescue it in a specific cell population. This provides information on the contribution of a specific cell type to the phenotype produced by the full $\mathrm{KO}$ of the protein. This technique employs a LoxP-flanked selectable neo marker and transcriptional/translational stop cassette (called neostop) located in the endogenous gene of interest to generate a null mutant that can be activated by Cre-mediated recombination. This construct is placed into a targeting vector, which is inserted into ES cells and introduced into the mouse genome through homologous recombination (Müller, 1999; Figure 1A) to eventually generate a mouse line in which expression of the targeted endogenous gene is suppressed. When this Cre responding mouse line is crossed with a transgenic line expressing Cre recombinase under a cell type-specific promoter, recombination of LoxP sites excises the neostop cassette, thus re-activating expression of the endogenous gene conditionally (Figure 1B) and with temporal control in a specific cell population (Figure 1C). This approach is powerful in the sense that it enables study of important questions regarding the phenotype reversibility of certain diseases involving the loss of a single gene function, and thus has the potential to open doors for future therapeutic approaches (Dragatsis and Zeitlin, 2001). By providing gain- and loss-of-function information, this approach has led to recent important steps forward in the understanding of the role of astrocytes in autism spectrum disorders.

\section{ROLE OF ASTROCYTE MeCP2 IN RETT'S SYNDROME}

Rett's syndrome (RTT) is an X-chromosome-linked autism spectrum disorder caused by the loss of function of the epigenetic factor methyl-CpG-binding protein 2 (MeCP2; Amir et al., 1999; Chahrour and Zoghbi, 2007). MeCP2 aberrations result in a constellation of neuropsychiatric, neuroanatomical, and neurophysiological abnormalities as well as autonomic dysfunctions, such as respiratory abnormalities. Delayed neuronal maturation and synaptogenesis, sparse and short dendritic spines (Fukuda et al., 2005), impaired synaptic transmission and plasticity (Dani et al., 2005; Asaka et al., 2006; Moretti et al., 2006), and altered number of glutamatergic synapses and expression of excitatory glutamate transporter VGLUT1 (Chao et al., 2007) were detected in global MeCP2 KO mouse lines (also called RTT mouse models). Although no unifying principle on MeCP2 function has yet emerged, it has been reported that MeCP2 acts as a transcriptional repressor, activator or RNA-binding protein (Nan et al., 1998; Colantuoni et al., 2001; Chahrour et al., 2008). Most studies have been directed toward understanding the in vivo mechanisms of neuronal MeCP2 (Akbarian et al., 2001) using different neuronal-specific cKO mouse models, which led to the thought that the primary cause of RTT is cell autonomous, i.e., resulting from a lack of functional MeCP2 in neurons (Chen et al., 2001; Guy et al., 2001; Luikenhuis et al., 2004). However, more recent studies have shown that $\mathrm{MeCP} 2$ is also expressed in all glial cell types, including astrocytes, oligodendrocyte progenitor cells, oligodendrocytes, and microglia (Ballas et al., 2009; Derecki et al., 2012). In particular, in vitro studies have shown that astrocytic MeCP2 supports normal neuronal morphology, indicating a non-cell autonomous influence of $\mathrm{MeCP} 2$ on neuronal function (Ballas et al., 2009; Maezawa et al., 2009). Global re-expression of the MeCP2 gene postnatally in full MeCP2 $\mathrm{KO}$ mice demonstrated disease reversibility in this RTT mouse model, suggesting that the neurological defects in MeCP2 disorders are not permanent (Guy etal., 2007). Based on these studies, Lioy et al. (2011) asked whether astrocytic MeCP2 may also have a role in rescuing RTT neuropathological symptoms in vivo in order to determine the contribution of astrocytes to the symptoms of RTT. They used a genetically engineered mouse line in which the endogenous MeCP2 gene is globally silenced by insertion of a LoxP-flanked stop cassette, but can be conditionally activated by stop cassette deletion via Cre-mediated excision (MeCP2 $2^{\text {lox-Stop }}$ mice; Guy et al., 2007). When these MeCP2 $2^{\text {lox-Stop }}$ mice were crossed with mice expressing $\mathrm{CreER}^{\mathrm{T} 2}$ under a human GFAP promoter (hGFAP-CreER ${ }^{\mathrm{T} 2}$ ), (Hirrlinger et al., 2006), the resulting new mouse line (MeCP2 $2^{\text {lox-Stop }:: h G F A P-C r e E R}{ }^{\mathrm{T} 2}$ ) was thus specifically designed for the investigation of astrocytic function 
in RTT (Lioy et al., 2011). The MeCP2 $2^{\text {lox-Stop ::hGFAP-CreER }}{ }^{\mathrm{T} 2}$ mice are globally deficient in MeCP2 until injected with tamoxifen, which induces the excision of the Lox-stop cassette in the endogenous $\mathrm{MeCP} 2$ gene, restoring the expression of $\mathrm{MeCP} 2$ in an astrocyte-specific manner. Strikingly, it was found that re-expression of MeCP2 specifically in astrocytes significantly improved locomotion, anxiety levels, breathing patterns, and average life span, indicating that astrocytes are involved in the neuropathology of RTT and that restoring astrocyte MeCP2 can ameliorate four consistent and robust RTT-like symptoms. Additionally, restoration of $\mathrm{MeCP} 2$ in astrocytes in the global $\mathrm{KO}$ mice exerted a non-cell-autonomous positive effect on $\mathrm{KO}$ neurons in vivo, restoring normal dendritic arborization and increasing levels of VGLUT1. Altogether, these findings suggest that astrocytic $\mathrm{MeCP} 2$ gene replacement is well-suited as a therapeutic strategy. Therefore, these findings have major implications not only for improving the understanding of astrocyte function in pathophysiology but also have valuable clinical implications (Gadalla et al., 2013; Garg etal., 2013). Deciphering the cellular (astrocyte vs. neuron) and molecular underpinnings of RTT is likely to contribute to the understanding of the pathogenesis of a broader class of autism spectrum disorders. Finally, the use of conditional endogenous gene repair mutations has a clear application for studying astrocytic contributions to other single gene diseases.

\section{VIRAL GENE TRANSDUCTION STRATEGIES}

A new technique that is gaining momentum in the study of astrocyte function is viral-mediated delivery of transgenic constructs to express or perturb a protein or molecule of interest. This strategy offers an attractive alternative to generation of transgenic mouse lines, which can be very time consuming and expensive due to costs associated with maintenance of animal lines and genotyping. Viral mediated gene delivery is reviewed in detail in this special issue (Merienne et al., 2013) and therefore this section will focus mainly on a particular application of this approach for the study of astrocyte $\mathrm{Ca}^{2+}$ activity.

Briefly, in these experiments, a transgenic construct is inserted into a recombinant $\mathrm{AAV}$ vector which is then injected into the brain of wild-type mice. Approximately 2 weeks is sufficient for the viral vector to be incorporated into the host genome and for high expression of the transgenic construct to occur (Ortinski et al., 2010; Xie et al., 2010; Shigetomi et al., 2013a). Several AAV serotypes have been generated that show tropism preferentially for neurons or astrocytes or a combination of cells (Ortinski et al., 2010). The AAV 2/5 pseudotype shows the strongest tropism for astrocytes and therefore appears to have emerged as the AAV construct of choice for viral vector targeting of astrocytes. Substitution of the CMV minimal promoter with an astrocyte-specific promoter derived from GFAP results in astrocyte-specific expression of the transgene.

An example of an application of this technique in the study of astrocyte biochemistry and function is recording $\mathrm{Ca}^{2+}$ fluctuations in astrocytes. Monitoring astrocyte $\mathrm{Ca}^{2+}$ activity continues to be a primary technique in the study of astrocytes ever since it was discovered in vitro that astrocyte $\mathrm{Ca}^{2+}$ elevations modulate neuronal excitability (Parpura et al., 1994; Araque etal.,
1998). Early approaches used commercially available membranepermeable AM ester forms of organic $\mathrm{Ca}^{2+}$ indicator dyes to "bulk-load" and monitor changes in cytosolic $\mathrm{Ca}^{2+}$ concentration in astrocytes (Porter and McCarthy, 1996; Nett et al., 2002). This technique offered the advantage of monitoring $\mathrm{Ca}^{2+}$ activity in many astrocytes simultaneously, but at the cost of poor resolution of astrocyte processes that are the first responders to neuronal activity and which may operate autonomously from other astrocytic compartments. A derivative of this technique developed more recently is "bolus-loading" in which the $\mathrm{AM} \mathrm{Ca}{ }^{2+}$ indicator is pressure-ejected to load astrocytes with $\mathrm{Ca}^{2+}$ indicator deeper in the tissue where cells and their connections are more intact (Garaschuk et al., 2006). While this technique increases visibility of the larger astrocyte processes, it still suffers from low signal-to-noise and difficulty differentiating between domains of individual astrocytes due to high background labeling. Furthermore, a secondary label, such as sulforhodamine 101, is often required to confirm the loaded cells as astrocytes (Nimmerjahn et al., 2004), but this indicator has been shown to alter neuronal activity (Kang et al., 2010). Moreover, cell-impermeant $\mathrm{Ca}^{2+}$ indicators delivered via patch pipette offer excellent signal-tonoise and detection of $\mathrm{Ca}^{2+}$ events in small, bulk fine processes of astrocytes (Fiacco et al., 2007; Xie et al., 2012), but there is some concern about dialysis of the cellular contents by the patch pipette, especially in cases where the pipette is left in wholecell patch clamp mode during measurements which can dampen $\mathrm{Ca}^{2+}$ signals. Last, while patch clamp delivery of $\mathrm{Ca}^{2+}$ indicator to astrocytes is relatively straightforward in brain slices, this approach is not as practical for recording astrocyte $\mathrm{Ca}^{2+}$ activity in vivo.

Viral-mediated delivery of GCaMP genetically encoded calcium indicators (GECIs) overcomes many of the limitations associated with the traditional approaches described above. It can be thought of as "high resolution bulk-loading" in that many astrocytes can be monitored at once and with the excellent signal-to-noise offered by the latest GCaMPs. Because the GECIs are delivered using an astrocyte-specific promoter, no secondary labeling is necessary to confirm the cells as astrocytes. Studies have indicated very specific transfection of astrocytes using this technique (Ortinski et al., 2010; Xie etal., 2010; Shigetomi et al., 2013a). Recently, Shigetomi etal. (2013a) used the AAV 2/5 vector to deliver a Lck membrane tethered form of GCaMP3 to astrocytes. Not only do the transfected astrocytes show significantly more frequent $\mathrm{Ca}^{2+}$ activity in fine processes compared to bulk-loading protocols (Shigetomi etal., 2013a), but because the indicator is membrane-tethered, it can monitor $\mathrm{Ca}^{2+}$ activity in the smallest "branchlets" and "leaflets" (Tong et al., 2013). Because $\mathrm{Ca}^{2+}$ activity monitored using the Lck-GCaMP3 indicator was diminished by an inhibitor of TRPA1 channels, the data provide evidence for astrocyte $\mathrm{Ca}^{2+}$ signals produced by a mechanism other than $\mathrm{IP}_{3} \mathrm{R} 2$-mediated internal stores. It will be important to follow-up this interesting finding in future studies by determining the relative ability of the Lck-GCaMP3 to detect TRPA1 vs. IP ${ }_{3} \mathrm{R}$-mediated $\mathrm{Ca}^{2+}$ elevations or mitochondrial $\mathrm{Ca}^{2+}$ dynamics (Parnis et al., 2013 ) in astrocytes. For example, how much of the $\mathrm{Ca}^{2+}$ activity detected by Lck-GCaMP3 is diminished by $\mathrm{IP}_{3} \mathrm{R}$ inhibitors? This would help rule out possible non-specific effects of HC 030031, 
the drug used to block TRPA1 channels. Firmer evidence of the TRPA1-mediated $\mathrm{Ca}^{2+}$ elevations could be provided by transfecting $\mathrm{IP}_{3} \mathrm{R} 2 \mathrm{KO}$ mice with the Lck-GCaMP3 $\mathrm{Ca}^{2+}$ indicator and determining the extent to which any remaining $\mathrm{Ca}^{2+}$ elevations are blocked by the TRPAl inhibitor. In summary, the membrane-tethered version of the new astrocytic GECIs may be specialized to distinguish among different sources of astrocyte $\mathrm{Ca}^{2+}$, due to a combination of its location, excellent signal-tonoise, and sensitivity to changes in $\mathrm{Ca}^{2+}$ concentration near the membrane.

Like any technique, viral delivery methods are not without limitations. GECIs have yet to be fully characterized. While they offer the advantage of increasing understanding of $\mathrm{Ca}^{2+}$ microdomains and conditions under which $\mathrm{Ca}^{2+}$ elevations occur, high levels of expression may result in significant calcium buffering with unintended consequences. Perhaps a more significant concern associated with the use of AAV vectors is the possibility of inducing reactive gliosis. Astrocytic $\mathrm{Ca}^{2+}$ signaling is disrupted in reactive astrocytes, with typically exaggerated and more widely propagating $\mathrm{Ca}^{2+}$ elevations and with increased propensity for gliotransmitter release (reviewed in Agulhon et al., 2012). Therefore, great care has been taken to determine the amount of reactive astrocytosis (if any) apparent after viral transfection by immunostaining for the astrocytic markers GFAP and vimentin to look for astrocytic hypertrophy (Xie et al., 2010; Shigetomi et al., 2013a). The AAV 2/5 vector was actually used purposefully to induce astrogliosis to determine the effect on astrocyte glutamine synthetase (GS) and neuronal excitability (Ortinski et al., 2010). Ortinski et al. (2010) found a significant increase in neuronal excitability caused by reduced GABA synthesis in neurons following loss of GS in reactive astrocytes. These data were confirmed by recovery of GABA transmission with exogenous application of glutamine. High titers of AAV 2/5 caused the astrogliosis and effects on neurons while low titers did not. Subsequent studies have actually used even higher titers than Ortinski et al. (2010), but reported normal astrocytic morphology suggesting that the astrocytes were not reactive (Xie etal., 2010; Shigetomi et al., 2013a). It is unclear what is behind these disparate findings but one possibility is that Ortinski et al. used the 638 bp GFAP Gfa104 promoter to target astrocytes, while Xie et al. (2010) and Shigetomi et al. (2013a,b) used the $681 \mathrm{bp}$ GFAP gfaABC $\mathrm{D}_{1} \mathrm{D}$ promoter. This is an important issue to continue to explore as there may be reactive changes induced by AAV in astrocytes that are underway prior to overt gliosis and hypertrophy. Because astrogliosis in itself significantly alters neuronal excitability, care needs to be taken interpreting the role of astrocyte $\mathrm{Ca}^{2+}$ on neuronal activity using virally transfected GECIs. Overall, the new astrocytic GECIs offer a tantalizing approach to record astrocyte $\mathrm{Ca}^{2+}$ activity in vivo. Future studies will help define limitations of viral-mediated GECI expression, leading to refinement in both methodology and interpretation of data.

\section{IN UTERO GENE ELECTROPORATION STRATEGIES}

One emerging methodology to manipulate gene expression in astrocytes in vivo is by IUE. IUE is a method of gene delivery into mouse embryos (Fukuchi-Shimogori and Grove, 2001;
Saito and Nakatsuji, 2001; Takahashi et al., 2002), which has become a method of choice for gain and loss of function studies in embryonic CNS cell progenitors. The IUE method involves injecting a plasmid DNA vector into the ventricles of the embryonic brain, and then using electrical pulses to facilitate the transfer of the DNA into the progenitor cells of the $\mathrm{VZ} /$ subventricular zone (SVZ). The optimal development stage for using this method in mice is between embryonic day (E) 10.5 and E16.5. In order to obtain stable expression of a transgene of interest in highly proliferative neural precursors and their progeny, a combination of transposon-mediated gene transfer into the host genome (Cary et al., 1989) with IUE has been used. This approach enables the expression of a transgene stably and efficiently in mitotic neural precursors (radial glia) during development, and in both cortical astrocytes and oligodendrocytes, after birth (Ding et al., 2005; Cadinanos and Bradley, 2007; Wilson et al., 2007; VandenDriessche et al., 2009; Woltjen et al., 2009; Yoshida et al., 2010; Chen and LoTurco, 2012). The transposon system involves a transgene of interest from a donor plasmid and a helper plasmid that expresses a transposase under the control of a cell-specific promoter (Cadinanos and Bradley, 2007; Chen and LoTurco, 2012). For instance, by combining a plasmid containing a transposase under the control of the GLAST promoter with a donor plasmid containing the green fluorescent marker eGFP, astrocytes originating from GLAST positive progenitors were labeled with eGFP in the cortex of P27 mice (Chen and LoTurco, 2012). Using an alternate transposon system and the GFAP and S100 $\beta$ promoters, stable postnatal expression of eGFP was obtained in astrocytes of juvenile mice (generated from GFAP- and S100 $\beta$-expressing progenitors; Yoshida et al., 2010). The relatively low number of astrocytes expressing eGFP allowed the authors to trace the long-term lineage of glial progenitors in vivo.

Tracing the long-term lineage of glial progenitor is of great importance in the field because of the growing evidence for astrocytic morphological, molecular, and functional heterogeneity. Whether this heterogeneity is specified during brain development is not clear. A recent study has addressed this question and analyzed cell lineages thoroughly using IUE (Garcia-Marques and Lopez-Mascaraque, 2013). Twelve plasmids containing the sequences of six fluorescent proteins, whose expression was driven by the GFAP promoter in either the cytosol or the nucleus, were used. After co-electroporation of the plasmid mixture with a plasmid encoding a transposase under the control of the ubiquitous CMV promoter into ventricles of E14 embryos, the sequences coding the fluorescent markers were randomly inserted into the genome of progenitor cells to generate many colors by a combination of the fluorescent proteins. This stochastic and combinatorial expression of six fluorescent proteins produces inheritable markers for in vivo long-term tracing of glial progenitor lineages (Garcia-Marques and Lopez-Mascaraque, 2013). Unanticipated and highly specific clonal distribution in specific domains was revealed in the cortex of adult mice. Moreover, the authors found that different classes of astrocytes emerge from different clones, reinforcing the view that lineage origin defines astrocyte heterogeneity. The positional identity of these clones represents an additional level of astrocytic 
heterogeneity, which is likely associated with specific regional functions. Interestingly, astrocytes of the same clone often (but not always) responded equally to cortical injury, suggesting the dependence of their genetic information. While some clones exhibited strong morphological alteration following injury, other clones located similar distances from the lesion were unresponsive, suggesting that the developmentally determined features of different astrocytic clones should not be overlooked when developing brain therapies (Martin-Lopez et al., 2013).

In addition to the use of astrocyte-specific promoters to drive transgene expression in postnatal astrocytes, conditional $\mathrm{CreER}^{\mathrm{T} 2}$ systems have also been combined with IUE to induce cell- and time-specific expression of transgenes (Matsuda and Cepko, 2007; LoTurco et al., 2009), widening the set of possible genetic manipulations using IUE. Therefore, although the IUE technology has been used mainly for descriptive analysis so far, it is likely to become an important tool more commonly used in the field. The relative ease of implementation and inherent flexibility of a plasmid-based system should make this method valuable to many investigators interested in marking and manipulating glial progenitor lineages in the CNS of species for which Cre reporter lines are not available (e.g., rats). Additionally, one of the advantages of the IUE approach over the generation of transgenic mice is that it is both cheaper and less time consuming. Furthermore, compared to surgical viral transfer performed postnatally, it is less invasive. The introduction of transgenes in astrocytes through IUE, when the immune system is immature, does not produce overt reactive gliosis thereby enabling study of astrocytes in a more physiological context compared to viral-based approaches. However, limitations of IUE include variable electroporation efficiency, promoter leakiness, and difficulty in precisely controlling the number of labeled astrocytes.

\section{STUDYING ASTROCYTE FUNCTION THROUGH GENETIC MANIPULATION OF HUMAN GLIAL PROGENITORS}

Although the molecular approaches described above have led to important steps forward in deciphering some of the functions of astrocytes in the pathophysiology of the mammalian brain, an important question remains: can the findings obtained from studies of the rodent brain be extrapolated to human astrocytes? There is mounting evidence that rodent astrocytes have multiple key functions in the developing and adult nervous system, including roles in synapse formation and function, working memory, autonomic and locomotor functions, and cognition (Barres, 2008; Halassa and Haydon, 2010; Lioy et al., 2011; Han et al., 2012; Molofsky et al., 2012; Wang et al., 2012a; Agulhon etal., 2013; Clarke and Barres, 2013). However, human astrocytes are both morphologically and functionally distinct from those of rodents (Colombo, 1996; Oberheim et al., 2009). Therefore, do human astrocytes have unique properties compared to their rodent counterparts, which could explain the higher cognitive abilities of humans? This fascinating question in the field has been recently explored by the groups of Maiken Nedergaard and Steven Goldman (Han et al., 2013).

In this study, the authors used human glial chimeric mouse brains to ask whether human astrocytes have unique properties that can influence activity-dependent synaptic plasticity ex vivo and learning and memory in vivo. To do so, they used human glial progenitor cells (GPCs) obtained by magnetic-assisted cell sorting using antibodies against PSA-NCAM and A5B5 cell surface antigens. The A2B5 ${ }^{+} / \mathrm{PSA}^{-\mathrm{NCAM}^{-}}$glial cells were expanded via a cell cultured protocol that promoted differentiation into astrocytes. Prior to transplantation into brains of neonatal immune-deficient mice, GPCs were transduced using a VSVg-pseudotyped lentiviralCMC-EGFP in order to label them with a GFP. Once transplanted, mice matured to become adult chimeras for both mouse and human astrocytes (Windrem et al., 2004, 2008), and their brains were analyzed in adult mice. Human-derived cells survived in the rodent host brains and infiltrated the cortex and hippocampus to give rise to some $\mathrm{EGFP}^{+}$astrocytes. Human astrocytes retained the large size and complex morphology that was previously reported in human brains (Oberheim et al., 2009), indicating that they matured in a cell-autonomous fashion. Additionally, human astrocytes extended processes contacting blood vessels and displayed long and tortuous processes, a phenotype typically observed in a specialized subpopulation of interlaminar astrocytes in the cortical white matter of adult human brains (Oberheim et al., 2009). Another type of engrafted human astroglial cell exhibited varicosity-studded processes (Kettenmann and Ransom, 2005; Oberheim et al., 2009). Finally, human astrocytes occupied distinct non-overlapping domains and formed gap junctions with rodent host astrocytes. At the physiological level, the input resistance of human astrocytes was twice as large as those of mouse astrocytes and $\mathrm{Ca}^{2+}$ signals propagated threefold faster than in mouse astrocytes. Notably, using acute hippocampal slices, Han et al. (2013) observed that the slope of fEPSPs was steeper and LTP was stronger and longer-lasting in mice grafted with human astrocytes compared to mice grafted with mouse astrocytes, indicating that excitatory synaptic transmission was enhanced in the presence of human astrocytes. Thus, enhancement of LTP was a specific characteristic of human glial cells. Interestingly, the potentiation of fEPSPs in human glial chimeric mice and the enhancement of LTP did not result from higher expression of NMDA receptors, increased synaptic release of glutamate, altered adenosine tone or increased glial release of D-serine. Rather it was found that human astrocytes facilitated synaptic insertion of the GluR1 subunit in host murine neurons through a TNF $\alpha$ dependent, PKC/CaMKII-mediated pathway, consistent with the potentiation of AMPA receptor-mediated currents, thus lowering the threshold for induction of LTP in human glial chimeric mice. Strikingly, human glial chimeric mice performed better in hippocampus-mediated learning tasks compared to their untransplanted littermates. Together, these findings suggest that human astrocytes may have some unique properties to enhance cognition. This study represents an important scientific and technological step forward to study the function of human astrocytes in live adult brains, which has not been possible so far. It also illustrates the power of combining different technological advancements together in live animals. It was unclear in the study if varicose projection astrocytes were present only in cortical layers 5 and 6 as discovered previously in human temporal neocortex, or if these cells were present throughout the cortex and hippocampus in the chimeric mice. Abnormal expression of varicose 
projection astrocytes in the hippocampus may in part explain some of the unique cognitive abilities in these animals. In addition, further investigation will be needed to determine whether the enhanced cognitive performance of the humanized mice is specifically due to human astrocytes, or whether the progenitor cells that did not differentiate into mature astrocytes contributed to the phenotype.

\section{SUMMARY AND FUTURE DIRECTIONS}

Important advances continue to be made in development of molecular tools to understand astrocyte function and the effect of manipulating individual astrocytic signaling molecules on neuronal activity and pathophysiology of the brain in vivo. Several examples have been provided in this review, including generation of conditional and inducible genetically engineered mouse lines for selective expression or removal of specific astrocyte proteins, as well as viral- or IUE-mediated gene delivery techniques for the study of astrocyte function. Study of astrocyte $\mathrm{Ca}^{2+}$ activity continues to be heavily emphasized, and while there is certainly more to discover in this area, there is an incredibly diverse array of other astrocytic GPCRs, ion channels, transporters, and signaling molecules to explore. Recent development of new lines using chemogenetics is one such example to further understand the importance of astrocytic signaling pathways in health and disease in vivo. The effect of selectively perturbing or stimulating other signaling molecules in astrocytes, such as $\mathrm{G}$ proteins, protein kinases, cAMP, diacylglycerol, phospholipase $\mathrm{C}$, and phosphoinositol isoforms may open up new areas of research on astrocytes. Furthermore, a greater appreciation of astrocyte heterogeneity in different brain areas or even between adjacent synapses calls for the need to develop selective markers to identify astrocyte subtypes and molecular approaches to manipulate specific astrocyte subpopulations. Another recent molecular approach only just underway is understanding the effects of enhanced DNA methylation or de-methylation (epigenetic mechanisms) on astrocyte protein expression and function in development and disease. Finally, there has been a strong tendency to focus on the immediate, short-term consequences of manipulating astrocyte receptors and signaling molecules on neuronal activity and brain function. Based on the predominance of metabotropic signaling cascades in astrocytes and the role of astrocytes in homeostasis of the synaptic microenvironment, the role of astrocyte-to-neuron communication may be tuned toward long-term regulatory functions. Therefore, another area of future study is to examine the outcome of stimulating astrocytic signaling cascades on gene transcription, synthesis of new proteins, and long-term regulation of cellular processes in neurons, astrocytes, and other glial cell types.

\section{ACKNOWLEDGMENTS}

Research in the authors' laboratories is supported by a grant (Chair of Excellence) from the Paris School of Neuroscience (Ecole des Neurosciences de Paris, ENP), a Marie Curie Career Integration grant, and an Ile-de-France Regional Council grant to Cendra Agulhon, as well as NIH NINDS R01NS082570 to Todd A. Fiacco. The content is solely the responsibility of the authors and does not necessarily represent the official views of the National Institutes of
Health. We apologize to those authors whose work we were unable to cite due to topic and space constraints.

\section{REFERENCES}

Achstatter, T., Moll, R., Anderson, A., Kuhn, C., Pitz, S., Schwechheimer, K., et al. (1986). Expression of glial filament protein (GFP) in nerve sheaths and non-neural cells re-examined using monoclonal antibodies, with special emphasis on the co-expression of GFP and cytokeratins in epithelial cells of human salivary gland and pleomorphic adenomas. Differentiation 31, 206-227. doi: 10.1111/j.1432-0436.1986.tb00401.x

Agulhon, C., Boyt, K. M., Xie, A. X., Friocourt, F., Roth, B. L., and McCarthy, K. (2013). Modulation of the autonomic nervous system by acute glial cell Gq-GPCR activation in vivo. J. Physiol. doi:10.1113/jphysiol.2013.261289

Agulhon, C., Fiacco, T. A., and McCarthy, K. D. (2010). Hippocampal short- and long-term plasticity are not modulated by astrocyte $\mathrm{Ca}^{2+}$ signaling. Science 327 , 1250-1254. doi: 10.1126/science.1184821

Agulhon, C., Petravicz, J., McMullen, A. B., Sweger, E. J., Minton, S. K., Taves, S. R., et al. (2008). What is the role of astrocyte calcium in neurophysiology? Neuron 59, 932-946. doi: 10.1016/j.neuron.2008.09.004

Agulhon, C., Sun, M. Y., Murphy, T., Myers, T., Lauderdale, K., and Fiacco, T. A. (2012). Calcium signaling and gliotransmission in normal vs. reactive astrocytes. Front. Pharmacol. 3:139. doi:10.3389/fphar.2012.00139

Akbarian, S., Chen, R. Z., Gribnau, J., Rasmussen, T. P., Fong, H., Jaenisch, R., etal. (2001). Expression pattern of the Rett syndrome gene MeCP2 in primate prefrontal cortex. Neurobiol. Dis. 8, 784-791. doi: 10.1006/nbdi. 2001.0420

Alexander, G. M., Rogan, S. C., Abbas, A. I., Armbruster, B. N., Pei, Y., Allen, J. A., et al. (2009). Remote control of neuronal activity in transgenic mice expressing evolved G protein-coupled receptors. Neuron 63, 27-39. doi: 10.1016/j.neuron.2009.06.014

Aley, P. K., Murray, H. J., Boyle, J. P., Pearson, H. A., and Peers, C. (2006). Hypoxia stimulates $\mathrm{Ca}^{2+}$ release from intracellular stores in astrocytes via cyclic ADP ribose-mediated activation of ryanodine receptors. Cell Calcium 39, 95-100. doi: 10.1016/j.ceca.2005.09.009

Alger, B. E. (2002). Retrograde signaling in the regulation of synaptic transmission: focus on endocannabinoids. Prog. Neurobiol. 68, 247-286. doi: 10.1016/S03010082(02)00080-1

Allen, J. A., Yost, J. M., Setola, V., Chen, X., Sassano, M. F., Chen, M., et al. (2011). Discovery of beta-arrestin-biased dopamine D2 ligands for probing signal transduction pathways essential for antipsychotic efficacy. Proc. Natl. Acad. Sci. U.S.A. 108, 18488-18493. doi: 10.1073/pnas.1104807108

Amir, R. E., Van den Veyver, I. B., Wan, M., Tran, C. Q., Francke, U., and Zoghbi, H. Y. (1999). Rett syndrome is caused by mutations in X-linked MECP2, encoding methyl-CpG-binding protein 2. Nat. Genet. 23, 185-188. doi: 10.1038/ 13810

Anthony, T. E., Klein, C., Fishell, G., and Heintz, N. (2004). Radial glia serve as neuronal progenitors in all regions of the central nervous system. Neuron 41, 881-890. doi: 10.1016/S0896-6273(04)00140-0

Araque, A., Parpura, V., Sanzgiri, R. P., and Haydon, P. G. (1998). Glutamatedependent astrocyte modulation of synaptic transmission between cultured hippocampal neurons. Eur. J. Neurosci. 10, 2129-2142. doi: 10.1046/j.14609568.1998.00221.x

Armbruster, B. N., Li, X., Pausch, M. H., Herlitze, S., and Roth, B. L. (2007). Evolving the lock to fit the key to create a family of $\mathrm{G}$ protein-coupled receptors potently activated by an inert ligand. Proc. Natl. Acad. Sci. U.S.A. 104, 5163-5168. doi: 10.1073/pnas.0700293104

Aronica, E., Gorter, J. A., Jansen, G. H., van Veelen, C. W., van Rijen, P. C., Ramkema, M., etal. (2003). Expression and cell distribution of group I and group II metabotropic glutamate receptor subtypes in Taylor-type focal cortical dysplasia. Epilepsia 44, 785-795. doi: 10.1046/j.1528-1157.2003. 54802.x

Asaka, Y., Jugloff, D. G., Zhang, L., Eubanks, J. H., and Fitzsimonds, R. M. (2006). Hippocampal synaptic plasticity is impaired in the Mecp2-null mouse model of Rett syndrome. Neurobiol. Dis. 21, 217-227. doi: 10.1016/j.nbd.2005.07.005

Atasoy, D., Betley, J. N., Su, H. H., and Sternson, S. M. (2012). Deconstruction of a neural circuit for hunger. Nature 488, 172-177. doi: 10.1038/nature11270

Audet, N., Charfi, I., Mnie-Filali, O., Amraei, M., Chabot-Dore, A. J., Millecamps, M., et al. (2012). Differential association of receptor-Gbetagamma 
complexes with beta-arrestin2 determines recycling bias and potential for tolerance of delta opioid receptor agonists. J. Neurosci. 32, 4827-4840. doi: 10.1523/JNEUROSCI.3734-11.2012

Bal, A., Bachelot, T., Savasta, M., Manier, M., Verna, J. M., Benabid, A. L., et al. (1994). Evidence for dopamine D2 receptor mRNA expression by striatal astrocytes in culture: in situ hybridization and polymerase chain reaction studies. Brain Res. Mol. Brain Res. 23, 204-212. doi: 10.1016/0169-328X(94)90227-5

Ballas, N., Lioy, D. T., Grunseich, C., and Mandel, G. (2009). Non-cell autonomous influence of MeCP2-deficient glia on neuronal dendritic morphology. Nat. Neurosci. 12, 311-317. doi: 10.1038/nn.2275

Baron, U., and Bujard, H. (2000). Tet repressor-based system for regulated gene expression in eukaryotic cells: principles and advances. Methods Enzymol. 327 401-421. doi: 10.1016/S0076-6879(00)27292-3

Barres, B. A. (2008). The mystery and magic of glia: a perspective on their roles in health and disease. Neuron 60, 430-440. doi: 10.1016/j.neuron.2008.10.013

Bellocchio, L., Lafenetre, P., Cannich, A., Cota, D., Puente, N., Grandes, P., et al. (2010). Bimodal control of stimulated food intake by the endocannabinoid system. Nat. Neurosci. 13, 281-283. doi: 10.1038/nn.2494

Bernal, G. M., and Peterson, D. A. (2011). Phenotypic and gene expression modification with normal brain aging in GFAP-positive astrocytes and neural stem cells. Aging Cell 10, 466-482. doi: 10.1111/j.1474-9726.2011.00694.x

Bezzi, P., Domercq, M., Brambilla, L., Galli, R., Schols, D., De Clercq, E., et al. (2001). CXCR4-activated astrocyte glutamate release via TNFalpha: amplification by microglia triggers neurotoxicity. Nat. Neurosci. 4, 702-710. doi: 10.1038/ 89490

Bhat, R., and Steinman, L. (2009). Innate and adaptive autoimmunity directed to the central nervous system. Neuron 64, 123-132. doi: 10.1016/j.neuron.2009.09.015

Blattermann, S., Peters, L., Ottersbach, P. A., Bock, A., Konya, V., Weaver, C. D., et al. (2012). A biased ligand for OXE-R uncouples Galpha and Gbetagamma signaling within a heterotrimer. Nat. Chem. Biol. 8, 631-638. doi: 10.1038/nchembio.962

Brambilla, R., Persaud, T., Hu, X., Karmally, S., Shestopalov, V. I., Dvoriantchikova G., et al. (2009). Transgenic inhibition of astroglial NF-kappa B improves functional outcome in experimental autoimmune encephalomyelitis by suppressing chronic central nervous system inflammation. J. Immunol. 182, 2628-2640. doi: 10.4049/jimmunol.0802954

Brenner, M. (1994). Structure and transcriptional regulation of the GFAP gene. Brain Pathol. 4, 245-257. doi: 10.1111/j.1750-3639.1994.tb00840.x

Brenner, M., Kisseberth, W. C., Su, Y., Besnard, F., and Messing, A. (1994). GFAP promoter directs astrocyte-specific expression in transgenic mice. J. Neurosci. 14 $1030-1037$.

Cadinanos, J., and Bradley, A. (2007). Generation of an inducible and optimized piggyBac transposon system. Nucleic Acids Res. 35, e87. doi: 10.1093/nar/gkm446

Capecchi, M. R. (1989). Altering the genome by homologous recombination. Science 244, 1288-1292. doi: 10.1126/science.2660260

Carlini, E. A. (2004). The good and the bad effects of (-) trans-delta-9tetrahydrocannabinol (delta 9-THC) on humans. Toxicon 44, 461-467. doi: 10.1016/j.toxicon.2004.05.009

Cary, L. C., Goebel, M., Corsaro, B. G., Wang, H. G., Rosen, E., and Fraser, M. J. (1989). Transposon mutagenesis of baculoviruses: analysis of Trichoplusia $\mathrm{n}$ transposon IFP2 insertions within the FP-locus of nuclear polyhedrosis viruses. Virology 172, 156-169. doi: 10.1016/0042-6822(89)90117-7

Casper, K. B., Jones, K., and McCarthy, K. D. (2007). Characterization of astrocytespecific conditional knockouts. Genesis 45, 292-299. doi: 10.1002/dvg.20287

Casper, K. B., and McCarthy, K. D. (2006). GFAP-positive progenitor cells produce neurons and oligodendrocytes throughout the CNS. Mol. Cell. Neurosci. 31, 676684. doi: 10.1016/j.mcn.2005.12.006

Chahrour, M., Jung, S. Y., Shaw, C., Zhou, X., Wong, S. T., Qin, J., et al. (2008). MeCP2, a key contributor to neurological disease, activates and represses transcription. Science 320, 1224-1229. doi: 10.1126/science.1153252

Chahrour, M., and Zoghbi, H. Y. (2007). The story of Rett syndrome: from clinic to neurobiology. Neuron 56, 422-437. doi: 10.1016/j.neuron.2007. 10.001

Chao, H. T., Zoghbi, H. Y., and Rosenmund, C. (2007). MeCP2 controls excitatory synaptic strength by regulating glutamatergic synapse number. Neuron 56, 58-65. doi: 10.1016/j.neuron.2007.08.018

Chen, F., and LoTurco, J. (2012). A method for stable transgenesis of radial glia lineage in rat neocortex by piggyBac mediated transposition. J. Neurosci. Methods 207, 172-180. doi: 10.1016/j.jneumeth.2012.03.016
Chen, N., Sugihara, H., Sharma, J., Perea, G., Petravicz, J., Le, C., et al. (2012). Nucleus basalis-enabled stimulus-specific plasticity in the visual cortex is mediated by astrocytes. Proc. Natl. Acad. Sci. U.S.A. 109, E2832-E2841. doi: 10.1073/pnas.1206557109

Chen, R. Z., Akbarian, S., Tudor, M., and Jaenisch, R. (2001). Deficiency of methylCpG binding protein-2 in CNS neurons results in a Rett-like phenotype in mice. Nat. Genet. 27, 327-331. doi: 10.1038/85906

Chevaleyre, V., Takahashi, K. A., and Castillo, P. E. (2006). Endocannabinoidmediated synaptic plasticity in the CNS. Annu. Rev. Neurosci. 29, 37-76. doi: 10.1146/annurev.neuro.29.051605.112834

Cho, A., Haruyama, N., and Kulkarni, A. B. (2009). Generation of transgenic mice. Curr. Protoc. Cell Biol. Chapter 19, Unit 19 11. doi:10.1002/0471143030.cb1911s42

Clarke, L. E., and Barres, B. A. (2013). Emerging roles of astrocytes in neural circuit development. Nat. Rev. Neurosci. 14, 311-321. doi: 10.1038/nrn3484

Colantuoni, C., Jeon, O. H., Hyder, K., Chenchik, A., Khimani, A. H., Narayanan V., et al. (2001). Gene expression profiling in postmortem Rett syndrome brain: differential gene expression and patient classification. Neurobiol. Dis. 8, 847-865. doi: 10.1006/nbdi.2001.0428

Colombo, J. A. (1996). Interlaminar astroglial processes in the cerebral cortex of adult monkeys but not of adult rats. Acta Anat. (Basel) 155, 57-62. doi: $10.1159 / 000147790$

Dani, V. S., Chang, Q., Maffei, A., Turrigiano, G. G., Jaenisch, R., and Nelson, S. B. (2005). Reduced cortical activity due to a shift in the balance between excitation and inhibition in a mouse model of Rett syndrome. Proc. Natl. Acad. Sci. U.S.A. 102, 12560-12565. doi: 10.1073/pnas.0506071102

Daniel-Christoph, W., Scheibe, J., Glocke, I., Weise, G., Deten, A., Boltze, J., et al. (2013). Object-based analysis of astroglial reaction and astrocyte subtype morphology after ischemic brain injury. Acta Neurobiol. Exp. (Wars) 73, 79-87.

Derecki, N. C., Cronk, J. C., Lu, Z., Xu, E., Abbott, S. B., Guyenet, P. G., et al. (2012). Wild-type microglia arrest pathology in a mouse model of Rett syndrome. Nature 484, 105-109. doi: 10.1038/nature10907

Devaraju, P., Sun, M. Y., Myers, T. L., Lauderdale, K., and Fiacco, T. A. (2013). Astrocytic group I mGluR-dependent potentiation of astrocytic glutamate and potassium uptake. J. Neurophysiol. 109, 2404-2414. doi: 10.1152/jn. 00517.2012

Di Castro, M. A., Chuquet, J., Liaudet, N., Bhaukaurally, K., Santello, M., Bouvier, D., et al. (2011). Local $\mathrm{Ca}^{2+}$ detection and modulation of synaptic release by astrocytes. Nat. Neurosci. 14, 1276-1284. doi: 10.1038/nn.2929

Di Marzo, V., Fontana, A., Cadas, H., Schinelli, S., Cimino, G., Schwartz, J. C., et al. (1994). Formation and inactivation of endogenous cannabinoid anandamide in central neurons. Nature 372, 686-691. doi: 10.1038/372686a0

Ding, S., Wu, X., Li, G., Han, M., Zhuang, Y., and Xu, T. (2005). Efficient transposition of the piggyBac (PB) transposon in mammalian cells and mice. Cell 122, 473-483. doi: 10.1016/j.cell.2005.07.013

Dong, X., Han, S., Zylka, M. J., Simon, M. I., and Anderson, D. J. (2001). A diverse family of GPCRs expressed in specific subsets of nociceptive sensory neurons. Cell 106, 619-632. doi: 10.1016/S0092-8674(01)00483-4

Dori, A., Cohen, J., Silverman, W. F., Pollack, Y., and Soreq, H. (2005). Functional manipulations of acetylcholinesterase splice variants highlight alternative splicing contributions to murine neocortical development. Cereb. Cortex 15, 419-430. doi: $10.1093 /$ cercor/bhh145

Dragatsis, I., and Zeitlin, S. (2001). A method for the generation of conditional gene repair mutations in mice. Nucleic Acids Res. 29, e10. doi: 10.1093/nar/29.3.e10

Eckardt, D., Theis, M., Degen, J., Ott, T., van Rijen, H. V., Kirchhoff, S., et al. (2004). Functional role of connexin43 gap junction channels in adult mouse heart assessed by inducible gene deletion. J. Mol. Cell. Cardiol. 36, 101-110. doi: 10.1016/j.yjmcc.2003.10.006

Emsley, J. G., and Macklis, J. D. (2006). Astroglial heterogeneity closely reflects the neuronal-defined anatomy of the adult murine CNS. Neuron Glia Biol. 2, 175-186. doi: 10.1017/S1740925X06000202

Eng, L. F. (1985). Glial fibrillary acidic protein (GFAP): the major protein of glial intermediate filaments in differentiated astrocytes. J. Neuroimmunol. 8, 203-214. doi: 10.1016/S0165-5728(85)80063-1

Eng, L. F., and Ghirnikar, R. S. (1994). GFAP and astrogliosis. Brain Pathol. 4, 229-237. doi: 10.1111/j.1750-3639.1994.tb00838.x

Eng, L. F., Ghirnikar, R. S., and Lee, Y. L. (2000). Glial fibrillary acidic protein: GFAP-thirty-one years (1969-2000). Neurochem. Res. 25, 1439-1451. doi: 10.1023/A:1007677003387 
Farina, C., Aloisi, F., and Meinl, E. (2007). Astrocytes are active players in cerebral innate immunity. Trends Immunol. 28, 138-145. doi: 10.1016/j.it.2007.01.005

Feil, R., Wagner, J., Metzger, D., and Chambon, P. (1997). Regulation of Cre recombinase activity by mutated estrogen receptor ligand-binding domains. Biochem. Biophys. Res. Commun. 237, 752-757. doi: 10.1006/bbrc.1997.7124

Ferguson, S. M., Eskenazi, D., Ishikawa, M., Wanat, M. J., Phillips, P. E., Dong, Y., et al. (2011). Transient neuronal inhibition reveals opposing roles of indirect and direct pathways in sensitization. Nat. Neurosci. 14, 22-24. doi: 10.1038/ nn. 2703

Fiacco, T. A., Agulhon, C., and McCarthy, K. D. (2009a). Sorting out astrocyte physiology from pharmacology. Annu. Rev. Pharmacol. Toxicol. 49, 151-174. doi: 10.1146/annurev.pharmtox.011008.145602

Fiacco, T. A., Casper, K., Sweger, E., Agulhon, C., Taves, S., Kurtzer-Minton, S., et al. (2009b). "Molecular approaches for studying astrocytes," in Astrocytes in (Patho)physiology of the Nervous System, eds V. Parpura and P. G. Haydon (New York, NY: Springer), 383-405.

Fiacco, T. A., Agulhon, C., Taves, S. R., Petravicz, J., Casper, K. B., Dong, X., etal. (2007). Selective stimulation of astrocyte calcium in situ does not affect neuronal excitatory synaptic activity. Neuron 54, 611-626. doi: 10.1016/j.neuron.2007.04.032

Figueiredo, M., Lane, S., Tang, F., Liu, B. H., Hewinson, J., Marina, N., et al. (2011). Optogenetic experimentation on astrocytes. Exp. Physiol. 96, 40-50. doi 10.1113/expphysiol.2010.052597

Freeman, M. R., and Rowitch, D. H. (2013). Evolving concepts of gliogenesis: a look way back and ahead to the next 25 years. Neuron 80, 613-623. doi: 10.1016/j.neuron.2013.10.034

Freund, T. F., Katona, I., and Piomelli, D. (2003). Role of endogenous cannabinoids in synaptic signaling. Physiol. Rev. 83, 1017-1066. doi: 10.1152/physrev.00004.2003

Fuchs, E., and Weber, K. (1994). Intermediate filaments: structure, dynamics, function, and disease. Annu. Rev. Biochem. 63, 345-382. doi 10.1146/annurev.bi.63.070194.002021

Fukuchi-Shimogori, T., and Grove, E. A. (2001). Neocortex patterning by the secreted signaling molecule FGF8. Science 294, 1071-1074. doi: 10.1126/science. 1064252

Fukuda, T., Itoh, M., Ichikawa, T., Washiyama, K., and Goto, Y. (2005). Delayed maturation of neuronal architecture and synaptogenesis in cerebral cortex of Mecp2-deficient mice. J. Neuropathol. Exp. Neurol. 64, 537-544.

Futatsugi, A., Nakamura, T., Yamada, M. K., Ebisui, E., Nakamura, K., Uchida, K., et al. (2005). IP3 receptor types 2 and 3 mediate exocrine secretion underlying energy metabolism. Science 309, 2232-2234. doi: 10.1126/science.1114110

Gadalla, K. K., Bailey, M. E., Spike, R. C., Ross, P. D., Woodard, K. T., Kalburgi, S. N., et al. (2013). Improved survival and reduced phenotypic severity following AAV9/MECP2 gene transfer to neonatal and juvenile male Mecp2 knockout mice. Mol. Ther. 21, 18-30. doi: 10.1038/mt.2012.200

Garaschuk, O., Milos, R. I., and Konnerth, A. (2006). Targeted bulk-loading of fluorescent indicators for two-photon brain imaging in vivo. Nat. Protoc. 1, 380 386. doi: $10.1038 /$ nprot. 2006.58

Garcia-Marques, J., and Lopez-Mascaraque, L. (2013). Clonal identity determines astrocyte cortical heterogeneity. Cereb. Cortex 23, 1463-1472. doi: 10.1093/cercor/bhs134

Gard, A. L., White, F. P., and Dutton, G. R. (1985). Extra-neural glial fibrillary acidic protein (GFAP) immunoreactivity in perisinusoidal stellate cells of rat liver. $J$. Neuroimmunol. 8, 359-375. doi: 10.1016/S0165-5728(85)80073-4

Garg, S. K., Lioy, D. T., Cheval, H., McGann, J. C., Bissonnette, J. M., Murtha, M. J., et al. (2013). Systemic delivery of MeCP2 rescues behavioral and cellular deficits in female mouse models of Rett syndrome. J. Neurosci. 33, 13612-13620. doi: 10.1523/JNEUROSCI.1854-13.2013

Garner, A. R., Rowland, D. C., Hwang, S. Y., Baumgaertel, K., Roth, B. L., Kentros, C., et al. (2012). Generation of a synthetic memory trace. Science 335, 1513-1516. doi: $10.1126 /$ science. 1214985

Gebski, B. L., Mann, C. J., Fletcher, S., and Wilton, S. D. (2003). Morpholino antisense oligonucleotide induced dystrophin exon 23 skipping in mdx mouse muscle. Hum. Mol. Genet. 12, 1801-1811. doi: 10.1093/hmg/ddg196

Gomi, H., Yokoyama, T., Fujimoto, K., Ikeda, T., Katoh, A., Itoh, T., et al. (1995). Mice devoid of the glial fibrillary acidic protein develop normally and are susceptible to scrapie prions. Neuron 14, 29-41. doi: 10.1016/0896-6273(95) 90238-4
Gomi, H., Yokoyama, T., and Itohara, S. (2010). Role of GFAP in morphological retention and distribution of reactive astrocytes induced by scrapie encephalopathy in mice. Brain Res. 1312, 156-167. doi: 10.1016/j.brainres.2009.11.025

Gossen, M., and Bujard, H. (1992). Tight control of gene expression in mammalian cells by tetracycline-responsive promoters. Proc. Natl. Acad. Sci. U.S.A. 89, 55475551. doi: 10.1073/pnas.89.12.5547

Gotz, M., Hartfuss, E., and Malatesta, P. (2002). Radial glial cells as neuronal precursors: a new perspective on the correlation of morphology and lineage restriction in the developing cerebral cortex of mice. Brain Res. Bull. 57, 777-788. doi: 10.1016/S0361-9230(01)00777-8

Grimm, D. (2006). Mouse genetics. A mouse for every gene. Science 312, 1862-1866. doi: $10.1126 /$ science.312.5782.1862

Grolla, A. A., Fakhfouri, G., Balzaretti, G., Marcello, E., Gardoni, F., Canonico, P. L., etal. (2013). Abeta leads to $\mathrm{Ca}^{(2+)}$ signaling alterations and transcriptional changes in glial cells. Neurobiol. Aging 34, 511-522. doi: 10.1016/j.neurobiolaging.2012.05.005

Gu, H., Marth, J. D., Orban, P. C., Mossmann, H., and Rajewsky, K. (1994). Deletion of a DNA polymerase beta gene segment in T cells using cell type-specific gene targeting. Science 265, 103-106. doi: 10.1126/science.8016642

Gustafsson, H., Virtanen, I., and Thornell, L. E. (1989). Glial fibrillary acidic protein and desmin in salivary neoplasms. Expression of four different types of intermediate filament proteins within the same cell type. Virchows Arch. B Cell Pathol. Incl. Mol. Pathol. 57, 303-313. doi: 10.1007/BF02899095

Guy, J., Gan, J., Selfridge, J., Cobb, S., and Bird, A. (2007). Reversal of neurological defects in a mouse model of Rett syndrome. Science 315, 1143-1147. doi: 10.1126/science. 1138389

Guy, J., Hendrich, B., Holmes, M., Martin, J. E., and Bird, A. (2001). A mouse Mecp2-null mutation causes neurological symptoms that mimic Rett syndrome. Nat. Genet. 27, 322-326. doi: 10.1038/85899

Hainfellner, J. A., Voigtlander, T., Strobel, T., Mazal, P. R., Maddalena, A. S., Aguzzi, A., et al. (2001). Fibroblasts can express glial fibrillary acidic protein (GFAP) in vivo. J. Neuropathol. Exp. Neurol. 60, 449-461.

Hajos, F. (2008). Changes in glial fibrillary acidic protein (GFAP) immonureactivity reflect neuronal states. Neurochem. Res. 33, 1643-1650. doi: 10.1007/s11064-0089745-2

Halassa, M. M., and Haydon, P. G. (2010). Integrated brain circuits: astrocytic networks modulate neuronal activity and behavior. Annu. Rev. Physiol. 72, 335355. doi: 10.1146/annurev-physiol-021909-135843

Hall, B., Limaye, A., and Kulkarni, A. B. (2009). Overview: generation of gene knockout mice. Curr. Protoc. Cell Biol. Chapter 19, Unit 19.12. 19.12.1-17. doi: 10.1002/0471143030.cb1912s44

Hall, W., Christie, M., and Currow, D. (2005). Cannabinoids and cancer: causation, remediation, and palliation. Lancet Oncol. 6, 35-42. doi: 10.1016/S14702045(04)01711-5

Hamby, M. E., Coppola, G., Ao, Y., Geschwind, D. H., Khakh, B. S., and Sofroniew, M. V. (2012). Inflammatory mediators alter the astrocyte transcriptome and calcium signaling elicited by multiple G-protein-coupled receptors. J. Neurosci. 32, 1448914510. doi: 10.1523/JNEUROSCI.1256-12.2012

Hamilton, N. B., and Attwell, D. (2010). Do astrocytes really exocytose neurotransmitters? Nat. Rev. Neurosci. 11, 227-238. doi: 10.1038/nrn2803

Han, J., Kesner, P., Metna-Laurent, M., Duan, T., Xu, L., Georges, F., et al. (2012). Acute cannabinoids impair working memory through astroglial CB1 receptor modulation of hippocampal LTD. Cell 148, 1039-1050. doi: 10.1016/j.cell.2012.01.037

Han, X., Chen, M., Wang, F., Windrem, M., Wang, S., Shanz, S., et al. (2013). Forebrain engraftment by human glial progenitor cells enhances synaptic plasticity and learning in adult mice. Cell Stem Cell 12, 342-353. doi: 10.1016/j.stem.2012.12.015

Hanbury, R., Ling, Z. D., Wuu, J., and Kordower, J. H. (2003). GFAP knockout mice have increased levels of GDNF that protect striatal neurons from metabolic and excitotoxic insults. J. Comp. Neurol. 461, 307-316. doi: 10.1002/cne.10667

Hayashi, S., and McMahon, A. P. (2002). Efficient recombination in diverse tissues by a tamoxifen-inducible form of Cre: a tool for temporally regulated gene activation/inactivation in the mouse. Dev. Biol. 244, 305-318. doi: 10.1006/dbio.2002.0597

Heifets, B. D., and Castillo, P. E. (2009). Endocannabinoid signaling and long-term synaptic plasticity. Annu. Rev. Physiol. 71, 283-306. doi: 10.1146/annurev.physiol.010908.163149 
Henneberger, C., Papouin, T., Oliet, S. H., and Rusakov, D. A. (2010). Long-term potentiation depends on release of D-serine from astrocytes. Nature 463, 232-236. doi: $10.1038 /$ nature 08673

Herkenham, M., Lynn, A. B., Little, M. D., Johnson, M. R., Melvin, L. S., de Costa B. R., et al. (1990). Cannabinoid receptor localization in brain. Proc. Natl. Acad. Sci. U.S.A. 87, 1932-1936. doi: 10.1073/pnas.87.5.1932

Hertle, D. N., and Yeckel, M. F. (2007). Distribution of inositol-1,4,5trisphosphate receptor isotypes and ryanodine receptor isotypes during maturation of the rat hippocampus. Neuroscience 150, 625-638. doi: 10.1016/j.neuroscience.2007.09.058

Hiller, C., Kling, R. C., Heinemann, F. W., Meyer, K., Hubner, H., and Gmeiner, P. (2013). Functionally selective dopamine D2/D3 receptor agonists comprising an enzyme moiety. J. Med. Chem. 56, 5130-5141. doi: 10.1021/jm400520c

Hirrlinger, P. G., Scheller, A., Braun, C., Hirrlinger, J., and Kirchhoff, F. (2006). Temporal control of gene recombination in astrocytes by transgenic expression of the tamoxifen-inducible DNA recombinase variant CreERT2. Glia 54, 11-20. doi: 10.1002/glia.20342

Holtzclaw, L. A., Pandhit, S., Bare, D. J., Mignery, G. A., and Russell, J. T. (2002). Astrocytes in adult rat brain express type 2 inositol 1,4,5-trisphosphate receptors. Glia 39, 69-84. doi: 10.1002/glia.10085

Iacobas, D. A., Scemes, E., and Spray, D. C. (2004). Gene expression alterations in connexin null mice extend beyond the gap junction. Neurochem. Int. 45, 243-250. doi: 10.1016/j.neuint.2003.12.008

Janigro, D., Gasparini, S., D’Ambrosio, R., McKhann, G. II., and DiFrancesco, D. (1997). Reduction of $\mathrm{K}^{+}$uptake in glia prevents long-term depression maintenance and causes epileptiform activity. J. Neurosci. 17, 2813-2824.

Jessen, K. R., Thorpe, R., and Mirsky, R. (1984). Molecular identity, distribution and heterogeneity of glial fibrillary acidic protein: an immunoblotting and immunohistochemical study of Schwann cells, satellite cells, enteric glia and astrocytes. J. Neurocytol. 13, 187-200. doi: 10.1007/BF01148114

Jin, K., Xie, L., Kim, S. H., Parmentier-Batteur, S., Sun, Y., Mao, X. O., et al. (2004) Defective adult neurogenesis in CB1 cannabinoid receptor knockout mice. Mol Pharmacol. 66, 204-208. doi: 10.1124/mol.66.2.204

Kaasinen, V., Vilkman, H., Hietala, J., Nagren, K., Helenius, H., Olsson, H., et al. (2000). Age-related dopamine D2/D3 receptor loss in extrastriatal regions of the human brain. Neurobiol. Aging 21, 683-688. doi: 10.1016/S0197-4580(00) 00149-4

Kang, J., Kang, N., Yu, Y., Zhang, J., Petersen, N., Tian, G. F., et al. (2010). Sulforhodamine 101 induces long-term potentiation of intrinsic excitability and synaptic efficacy in hippocampal CA1 pyramidal neurons. Neuroscience 169, 1601-1609. doi: 10.1016/j.neuroscience.2010.06.020

Kano, M., Ohno-Shosaku, T., Hashimotodani, Y., Uchigashima, M., and Watanabe, M. (2009). Endocannabinoid-mediated control of synaptic transmission. Physiol. Rev. 89, 309-380. doi: 10.1152/physrev.00019.2008

Kato, A., Punnakkal, P., Pernia-Andrade, A. J., von Schoultz, C., Sharopov, S., Nyilas, R., et al. (2012). Endocannabinoid-dependent plasticity at spinal nociceptor synapses. J. Physiol. 590, 4717-4733. doi: 10.1113/jphysiol.2012.234229

Kato, H., Yamamoto, T., Yamamoto, H., Ohi, R., So, N., and Iwasaki, Y. (1990). Immunocytochemical characterization of supporting cells in the enteric nervous system in Hirschsprung's disease. J. Pediatr. Surg. 25, 514-519. doi: 10.1016/0022 3468(90)90563-O

Kawamura, Y., Fukaya, M., Maejima, T., Yoshida, T., Miura, E., Watanabe, M. et al. (2006). The CB1 cannabinoid receptor is the major cannabinoid receptor at excitatory presynaptic sites in the hippocampus and cerebellum. J. Neurosci. 26, 2991-3001. doi: 10.1523/JNEUROSCI.4872-05.2006

Kettenmann, H., and Ransom, B. R. (2005). Neuroglia. New York: Oxford University Press.

Khan, Z. U., Koulen, P., Rubinstein, M., Grandy, D. K., and Goldman-Rakic, P. S. (2001). An astroglia-linked dopamine D2-receptor action in prefrontal cortex. Proc. Natl. Acad. Sci. U.S.A. 98, 1964-1969. doi: 10.1073/pnas.98.4.1964

Kinouchi, R., Takeda, M., Yang, L., Wilhelmsson, U., Lundkvist, A., Pekny, M., et al. (2003). Robust neural integration from retinal transplants in mice deficient in GFAP and vimentin. Nat. Neurosci. 6, 863-868. doi: 10.1038/nn1088

Kirchhoff, F. (2010). Neuroscience. Questionable calcium. Science 327, 1212-1213. doi: $10.1126 /$ science. 1187420

Kreitzer, A. C., and Regehr, W. G. (2001). Retrograde inhibition of presynaptic calcium influx by endogenous cannabinoids at excitatory synapses onto Purkinje cells. Neuron 29, 717-727. doi: 10.1016/S0896-6273(01)00246-X
Kuchibhotla, K. V., Lattarulo, C. R., Hyman, B. T., and Bacskai, B. J. (2009). Synchronous hyperactivity and intercellular calcium waves in astrocytes in Alzheimer mice. Science 323, 1211-1215. doi: 10.1126/science. 1169096

Lee, Y., Su, M., Messing, A., and Brenner, M. (2006). Astrocyte heterogeneity revealed by expression of a GFAP-LacZ transgene. Glia 53, 677-687. doi: 10.1002/glia.20320

Lemberger, L. (1980). Potential therapeutic usefulness of marijuana. Annu. Rev. Pharmacol. Toxicol. 20, 151-172. doi: 10.1146/annurev.pa.20.040180.001055

Lewis, S. A., Balcarek, J. M., Krek, V., Shelanski, M., and Cowan, N. J. (1984). Sequence of a cDNA clone encoding mouse glial fibrillary acidic protein: structural conservation of intermediate filaments. Proc. Natl. Acad. Sci. U.S.A. 81, 2743-2746. doi: 10.1073/pnas.81.9.2743

Li, X., Zima, A. V., Sheikh, F., Blatter, L. A., and Chen, J. (2005). Endothelin1-induced arrhythmogenic $\mathrm{Ca}^{2+}$ signaling is abolished in atrial myocytes of inositol-1,4,5-trisphosphate(IP3)-receptor type 2-deficient mice. Circ. Res. 96, 1274-1281. doi: 10.1161/01.RES.0000172556.05576.4c

Lichtman, A. H., and Martin, B. R. (1996). Delta 9-tetrahydrocannabinol impairs spatial memory through a cannabinoid receptor mechanism. Psychopharmacology (Berl.) 126, 125-131. doi: 10.1007/BF02246347

Liedtke, W., Edelmann, W., Bieri, P. L., Chiu, F. C., Cowan, N. J., Kucherlapati, R., et al. (1996). GFAP is necessary for the integrity of CNS white matter architecture and long-term maintenance of myelination. Neuron 17, 607-615. doi: 10.1016/S0896-6273(00)80194-4

Liedtke, W., Edelmann, W., Chiu, F. C., Kucherlapati, R., and Raine, C. S. (1998). Experimental autoimmune encephalomyelitis in mice lacking glial fibrillary acidic protein is characterized by a more severe clinical course and an infiltrative central nervous system lesion. Am. J. Pathol. 152, 251-259.

Limaye, A., Hall, B., and Kulkarni, A. B. (2009). Manipulation of mouse embryonic stem cells for knockout mouse production. Curr. Protoc. Cell Biol. Chapter 19, Unit 19. 13. 19. 13.1-24. doi: 10.1002/0471143030.cb1913s44

Lioy, D. T., Garg, S. K., Monaghan, C. E., Raber, J., Foust, K. D., Kaspar, B. K., et al. (2011). A role for glia in the progression of Rett's syndrome. Nature 475, 497-500. doi: $10.1038 /$ nature 10214

LoTurco, J., Manent, J. B., and Sidiqi, F. (2009). New and improved tools for in utero electroporation studies of developing cerebral cortex. Cereb. Cortex 19 (Suppl. 1), i120-i125. doi: 10.1093/cercor/bhp033

Lucas, S. M., Rothwell, N. J., and Gibson, R. M. (2006). The role of inflammation in CNS injury and disease. Br. J. Pharmacol. 147(Suppl. 1), S232-S240. doi: 10.1038/sj.bjp.0706400

Luikenhuis, S., Giacometti, E., Beard, C. F., and Jaenisch, R. (2004). Expression of MeCP2 in postmitotic neurons rescues Rett syndrome in mice. Proc. Natl. Acad. Sci. U.S.A. 101, 6033-6038. doi: 10.1073/pnas.0401626101

Luo, X., Zhang, X., Shao, W., Yin, Y., and Zhou, J. (2009). Crucial roles of MZF-1 in the transcriptional regulation of apomorphine-induced modulation of FGF-2 expression in astrocytic cultures. J. Neurochem. 108, 952-961. doi: 10.1111/j.14714159.2008.05845.x

Maezawa, I., Swanberg, S., Harvey, D., LaSalle, J. M., and Jin, L. W. (2009). Rett syndrome astrocytes are abnormal and spread MeCP2 deficiency through gap junctions. J. Neurosci. 29, 5051-5061. doi: 10.1523/JNEUROSCI.032409.2009

Malatesta, P., Hack, M. A., Hartfuss, E., Kettenmann, H., Klinkert, W., Kirchhoff, F., et al. (2003). Neuronal or glial progeny: regional differences in radial glia fate. Neuron 37, 751-764. doi: 10.1016/S0896-6273(03)00116-8

Maldonado, R., Valverde, O., and Berrendero, F. (2006). Involvement of the endocannabinoid system in drug addiction. Trends Neurosci. 29, 225-232. doi: 10.1016/j.tins.2006.01.008

Mansuy, I. M., and Bujard, H. (2000). Tetracycline-regulated gene expression in the brain. Curr. Opin. Neurobiol. 10, 593-596. doi: 10.1016/S0959-4388(00)00127-6 Marsicano, G., Goodenough, S., Monory, K., Hermann, H., Eder, M., Cannich, A., et al. (2003). CB1 cannabinoid receptors and on-demand defense against excitotoxicity. Science 302, 84-88. doi: 10.1126/science. 1088208

Marsicano, G., Wotjak, C. T., Azad, S. C., Bisogno, T., Rammes, G., Cascio, M. G., et al. (2002). The endogenous cannabinoid system controls extinction of aversive memories. Nature 418, 530-534. doi: 10.1038/nature00839

Martin-Lopez, E., Garcia-Marques, J., Nunez-Llaves, R., and Lopez-Mascaraque, L. (2013). Clonal astrocytic response to cortical injury. PLoS ONE 8:e74039. doi:10.1371/journal.pone.0074039 
Masood, K., Besnard, F., Su, Y., and Brenner, M. (1993). Analysis of a segment of the human glial fibrillary acidic protein gene that directs astrocyte-specific transcription. J. Neurochem. 61, 160-166. doi: 10.1111/j.1471-4159.1993.tb03551.x

Matsuda, L. A., Lolait, S. J., Brownstein, M. J., Young, A. C., and Bonner, T. I. (1990). Structure of a cannabinoid receptor and functional expression of the cloned cDNA. Nature 346, 561-564. doi: 10.1038/346561a0

Matsuda, T., and Cepko, C. L. (2007). Controlled expression of transgenes introduced by in vivo electroporation. Proc. Natl. Acad. Sci. U.S.A. 104, 1027-1032. doi: 10.1073/pnas.0610155104

Matsumoto, M., Nakagawa, T., Inoue, T., Nagata, E., Tanaka, K., Takano, H. et al. (1996). Ataxia and epileptic seizures in mice lacking type 1 inosito 1,4,5-trisphosphate receptor. Nature 379, 168-171. doi: 10.1038/379168a0

Matyash, V., and Kettenmann, H. (2010). Heterogeneity in astrocyte morphology and physiology. Brain Res. Rev. 63, 2-10. doi: 10.1016/j.brainresrev.2009.12.001

McCall, M. A., Gregg, R. G., Behringer, R. R., Brenner, M., Delaney, C. L., Galbreath, E. J., et al. (1996). Targeted deletion in astrocyte intermediate filament (Gfap) alters neuronal physiology. Proc. Natl. Acad. Sci. U.S.A. 93, 6361-6366. doi: 10.1073/pnas.93.13.6361

Menet, V., Prieto, M., Privat, A., and Gimenez y Ribotta, M. (2003). Axonal plasticity and functional recovery after spinal cord injury in mice deficient in both glia fibrillary acidic protein and vimentin genes. Proc. Natl. Acad. Sci. U.S.A. 100 8999-9004. doi: 10.1073/pnas.1533187100

Merienne, N., Le Douce, J., Faivre, E., Deglon, N., and Bonvento, G. (2013). Efficien gene delivery and selective transduction of astrocytes in the mammalian brain using viral vectors. Front. Cell Neurosci. 7:106. doi:10.3389/fncel.2013.00106

Merkle, F. T., Tramontin, A. D., Garcia-Verdugo, J. M., and Alvarez-Buylla, A. (2004). Radial glia give rise to adult neural stem cells in the subventricular zone. Proc. Natl. Acad. Sci. U.S.A. 101, 17528-17532. doi: 10.1073/pnas.0407893101

Middeldorp, J., and Hol, E. M. (2011). GFAP in health and disease. Prog. Neurobiol. 93, 421-443. doi: 10.1016/j.pneurobio.2011.01.005

Missale, C., Nash, S. R., Robinson, S. W., Jaber, M., and Caron, M. G. (1998). Dopamine receptors: from structure to function. Physiol. Rev. 78, 189-225.

Molofsky, A. V., Krencik, R., Ullian, E. M., Tsai, H. H., Deneen, B., Richardson, W. D., et al. (2012). Astrocytes and disease: a neurodevelopmental perspective. Genes Dev. 26, 891-907. doi: 10.1101/gad.188326.112

Monory, K., Massa, F., Egertova, M., Eder, M., Blaudzun, H., Westenbroek, R., et al. (2006). The endocannabinoid system controls key epileptogenic circuits in the hippocampus. Neuron 51, 455-466. doi: 10.1016/j.neuron.2006.07.006

Moretti, P., Levenson, J. M., Battaglia, F., Atkinson, R., Teague, R., Antalffy, B., et al. (2006). Learning and memory and synaptic plasticity are impaired in a mouse model of Rett syndrome. J. Neurosci. 26, 319-327. doi 10.1523/JNEUROSCI.2623-05.2006

Mori, T., Tanaka, K., Buffo, A., Wurst, W., Kuhn, R., and Gotz, M. (2006). Inducible gene deletion in astroglia and radial glia: a valuable tool for functional and lineage analysis. Glia 54, 21-34. doi: 10.1002/glia.20350

Moroy, T., and Heyd, F. (2007). The impact of alternative splicing in vivo: mouse models show the way. RNA 13, 1155-1171. doi: 10.1261/rna.554607

Morozov, A., Kellendonk, C., Simpson, E., and Tronche, F. (2003). Using conditional mutagenesis to study the brain. Biol. Psychiatry 54, 1125-1133. doi: 10.1016/S0006-3223(03)00467-0

Müller, U. (1999). Ten years of gene targeting: targeted mouse mutants, from vector design to phenotype analysis. Mech. Dev. 82, 3-21. doi: 10.1016/S09254773(99)00021-0

Nan, X., Ng, H. H., Johnson, C. A., Laherty, C. D., Turner, B. M., Eisenman, R. N., et al. (1998). Transcriptional repression by the methyl-CpG-binding protein MeCP2 involves a histone deacetylase complex. Nature 393, 386-389. doi: $10.1038 / 30764$

Navarrete, M., and Araque, A. (2008). Endocannabinoids mediate neuron-astrocyte communication. Neuron 57, 883-893. doi: 10.1016/j.neuron.2008.01.029

Navarrete, M., and Araque, A. (2010). Endocannabinoids potentiate synaptic transmission through stimulation of astrocytes. Neuron 68, 113-126. doi 10.1016/j.neuron.2010.08.043

Navarrete, M., Perea, G., Fernandez de Sevilla, D., Gomez-Gonzalo, M., Nunez, A., Martin, E. D., et al. (2012). Astrocytes mediate in vivo cholinergic-induced synaptic plasticity. PLoS Biol. 10:e1001259. doi:10.1371/journal.pbio.1001259

Nawashiro, H., Brenner, M., Fukui, S., Shima, K., and Hallenbeck, J. M. (2000). High susceptibility to cerebral ischemia in GFAP-null mice. J. Cereb. Blood Flow Metab. 20, 1040-1044. doi: 10.1097/00004647-200007000-00003
Nawashiro, H., Messing, A., Azzam, N., and Brenner, M. (1998). Mice lacking GFAP are hypersensitive to traumatic cerebrospinal injury. Neuroreport 9, 1691-1696. doi: 10.1097/00001756-199806010-00004

Nedergaard, M., and Verkhratsky, A. (2012). Artifact versus reality: how astrocytes contribute to synaptic events. Glia 60, 1013-1023. doi: 10.1002/glia.22288

Nett, W. J., Oloff, S. H., and McCarthy, K. D. (2002). Hippocampal astrocytes in situ exhibit calcium oscillations that occur independent of neuronal activity. $J$. Neurophysiol. 87, 528-537.

Nimmerjahn, A., Kirchhoff, F., Kerr, J. N., and Helmchen, F. (2004). Sulforhodamine 101 as a specific marker of astroglia in the neocortex in vivo. Nat. Methods 1, 31-37. doi: 10.1038/nmeth706

Oberheim, N. A., Goldman, S. A., and Nedergaard, M. (2012). Heterogeneity of astrocytic form and function. Methods Mol. Biol. 814, 23-45. doi: 10.1007/978-161779-452-0_3

Oberheim, N. A., Takano, T., Han, X., He, W., Lin, J. H., Wang, F., et al. (2009). Uniquely hominid features of adult human astrocytes. J. Neurosci. 29, 3276-3287. doi: 10.1523/JNEUROSCI.4707-08.2009

Ortinski, P. I., Dong, J., Mungenast, A., Yue, C., Takano, H., Watson, D. J., et al. (2010). Selective induction of astrocytic gliosis generates deficits in neuronal inhibition. Nat. Neurosci. 13, 584-591. doi: 10.1038/nn.2535

Otani, N., Nawashiro, H., Fukui, S., Ooigawa, H., Ohsumi, A., Toyooka, T., etal. (2006). Enhanced hippocampal neurodegeneration after traumatic or kainate excitotoxicity in GFAP-null mice. J. Clin. Neurosci. 13, 934-938. doi: 10.1016/j.jocn.2005.10.018

Ousman, S. S., Tomooka, B. H., van Noort, J. M., Wawrousek, E. F., O'Connor, K. C., Hafler, D. A., et al. (2007). Protective and therapeutic role for alphaB-crystallin in autoimmune demyelination. Nature 448, 474-479. doi: 10.1038/nature05935

Parnis, J., Montana, V., Delgado-Martinez, I., Matyash, V., Parpura, V., Kettenmann, H., et al. (2013). Mitochondrial exchanger NCLX plays a major role in the intracellular $\mathrm{Ca}^{2+}$ signaling, gliotransmission, and proliferation of astrocytes. $J$. Neurosci. 33, 7206-7219. doi: 10.1523/JNEUROSCI.5721-12.2013

Parpura, V., Basarsky, T. A., Liu, F., Jeftinija, K., Jeftinija, S., and Haydon, P. G. (1994). Glutamate-mediated astrocyte-neuron signalling. Nature 369, 744-747. doi: $10.1038 / 369744 \mathrm{a} 0$

Pascual, O., Ben Achour, S., Rostaing, P., Triller, A., and Bessis, A. (2012). Microglia activation triggers astrocyte-mediated modulation of excitatory neurotransmission. Proc. Natl. Acad. Sci. U.S.A. 109, E197-E205. doi: 10.1073/pnas. 1111098109

Pekny, M., Leveen, P., Pekna, M., Eliasson, C., Berthold, C. H., Westermark, B., et al. (1995). Mice lacking glial fibrillary acidic protein display astrocytes devoid of intermediate filaments but develop and reproduce normally. EMBO J. 14, 1590-1598.

Pekny, M., and Nilsson, M. (2005). Astrocyte activation and reactive gliosis. Glia 50, 427-434. doi: 10.1002/glia.20207

Pekny, M., and Pekna, M. (2004). Astrocyte intermediate filaments in CNS pathologies and regeneration. J. Pathol. 204, 428-437. doi: 10.1002/path.1645

Peng, H., Erdmann, N., Whitney, N., Dou, H., Gorantla, S., Gendelman, H. E., et al. (2006). HIV-1-infected and/or immune activated macrophages regulate astrocyte SDF-1 production through IL-1beta. Glia 54, 619-629. doi: 10.1002/glia.20409

Petravicz, J., Fiacco, T. A., and McCarthy, K. D. (2008). Loss of IP3 receptordependent $\mathrm{Ca}^{2+}$ increases in hippocampal astrocytes does not affect baseline CA1 pyramidal neuron synaptic activity. J. Neurosci. 28, 4967-4973. doi: 10.1523/JNEUROSCI.5572-07.2008

Pfrieger, F. W., and Slezak, M. (2012). Genetic approaches to study glial cells in the rodent brain. Glia 60, 681-701. doi: 10.1002/glia.22283

Porter, J. T., and McCarthy, K. D. (1996). Hippocampal astrocytes in situ respond to glutamate released from synaptic terminals. J. Neurosci. 16, 5073-5081.

Porter, J. T., and McCarthy, K. D. (1997). Astrocytic neurotransmitter receptors in situ and in vivo. Prog. Neurobiol. 51, 439-455. doi: 10.1016/S03010082(96)00068-8

Ranganathan, M., and D'Souza, D. C. (2006). The acute effects of cannabinoids on memory in humans: a review. Psychopharmacology (Berl.) 188, 425-444. doi: 10.1007/s00213-006-0508-y

Reeves, S. A., Helman, L. J., Allison, A., and Israel, M. A. (1989). Molecular cloning and primary structure of human glial fibrillary acidic protein. Proc. Natl. Acad. Sci. U.S.A. 86, 5178-5182. doi: 10.1073/pnas.86.13.5178

Riol, H., Tardy, M., Rolland, B., Levesque, G., and Murthy, M. R. (1997). Detection of the peripheral nervous system (PNS)-type glial fibrillary acidic 
protein (GFAP) and its mRNA in human lymphocytes. J. Neurosci. Res. 48, 53-62. doi: 10.1002/(SICI)1097-4547(19970401)48:1<53::AID-JNR5>3.0. $\mathrm{CO} ; 2-\mathrm{D}$

Saito, T., and Nakatsuji, N. (2001). Efficient gene transfer into the embryonic mouse brain using in vivo electroporation. Dev. Biol. 240, 237-246. doi: 10.1006/dbio.2001.0439

Sauer, B. (1998). Inducible gene targeting in mice using the Cre/lox system. Methods 14, 381-392. doi: 10.1006/meth.1998.0593

Saunders, T. L. (2011). Inducible transgenic mouse models. Methods Mol. Biol. 693 103-115. doi: 10.1007/978-1-60761-974-1_7

Schreiner, A. E., Durry, S., Aida, T., Stock, M. C., Ruther, U., Tanaka, K., et al. (2013). Laminar and subcellular heterogeneity of glast and GLT-1 immunoreactivity in the developing postnatal mouse hippocampus. J. Comp. Neurol. doi:10.1002/cne.23450 [Epub ahead of print].

Serrano, A., Haddjeri, N., Lacaille, J. C., and Robitaille, R. (2006). GABAergic network activation of glial cells underlies hippocampal heterosynaptic depression. J. Neurosci. 26, 5370-5382. doi: 10.1523/JNEUROSCI.5255-05.2006

Shao, W., Zhang, S. Z., Tang, M., Zhang, X. H., Zhou, Z., Yin, Y. Q., et al. (2013). Suppression of neuroinflammation by astrocytic dopamine D2 receptors via alphaB-crystallin. Nature 494, 90-94. doi: 10.1038/nature11748

Sharp, A. H., Nucifora, F. C. Jr., Blondel, O., Sheppard, C. A., Zhang, C. Snyder, S. H., et al. (1999). Differential cellular expression of isoforms of inositol 1,4,5-triphosphate receptors in neurons and glia in brain. J. Comp. Neurol. 406, 207-220. doi: 10.1002/(SICI)1096-9861(19990405)406:2<207::AIDCNE6>3.0.CO;2-7

Shibuki, K., Gomi, H., Chen, L., Bao, S., Kim, J. J., Wakatsuki, H., et al. (1996). Deficient cerebellar long-term depression, impaired eyeblink conditioning, and normal motor coordination in GFAP mutant mice. Neuron 16, 587-599. doi: 10.1016/S0896-6273(00)80078-1

Shigetomi, E., Bushong, E. A., Haustein, M. D., Tong, X., and Jackson-Weaver, O., and Kracun, S. (2013a). Imaging calcium microdomains within entire astrocyte territories and endfeet with GCaMPs expressed using adeno-associated viruses. J. Gen. Physiol. 141, 633-647. doi: 10.1085/jgp.201210949

Shigetomi, E., Jackson-Weaver, O., Huckstepp, R. T., O’Dell T. J., and Khakh, B. S. (2013b). TRPA1 channels are regulators of astrocyte basal calcium levels and longterm potentiation via constitutive D-serine release. J. Neurosci. 33, 10143-10153. doi: 10.1523/JNEUROSCI.5779-12.2013

Sikorski, R., and Peters, R. (1997). Transgenics on the internet. Nat. Biotechnol. 15, 289. doi: $10.1038 /$ nbt0397-289

Sofroniew, M. V. (2009). Molecular dissection of reactive astrogliosis and glial scar formation. Trends Neurosci. 32, 638-647. doi: 10.1016/j.tins.2009.08.002

Sofroniew, M. V., and Vinters, H. V. (2010). Astrocytes: biology and pathology. Acto Neuropathol. 119, 7-35. doi: 10.1007/s00401-009-0619-8

Sosunov, A. A., Guilfoyle, E., Wu, X., McKhann, G. M. II., and Goldman, J. E. (2013). Phenotypic conversions of "protoplasmic" to "reactive" astrocytes in Alexander disease. J. Neurosci. 33, 7439-7450. doi: 10.1523/JNEUROSCI.4506-12. 2013

Steele, M. L., and Robinson, S. R. (2012). Reactive astrocytes give neurons less support: implications for Alzheimer's disease. Neurobiol. Aging 33, 423, el-e13. doi: 10.1016/j.neurobiolaging.2010.09.018

Sternberg, N., and Hamilton, D. (1981). Bacteriophage P1 site-specific recombination. I. Recombination between loxP sites. J. Mol. Biol. 150, 467-486. doi 10.1016/0022-2836(81)90375-2

Takahashi, M., Sato, K., Nomura, T., and Osumi, N. (2002). Manipulating gene expressions by electroporation in the developing brain of mammalian embryos. Differentiation 70, 155-162. doi: 10.1046/j.1432-0436.2002.700405.x

Takano, T., Han, X., Deane, R., Zlokovic, B., and Nedergaard, M. (2007). Two-photon imaging of astrocytic $\mathrm{Ca}^{2+}$ signaling and the microvasculature in experimental mice models of Alzheimer's disease. Ann. N.Y. Acad. Sci. 1097, 40-50. doi: 10.1196/annals.1379.004

Takata, N., Mishima, T., Hisatsune, C., Nagai, T., Ebisui, E., Mikoshiba, K., et al. (2011). Astrocyte calcium signaling transforms cholinergic modulation to cortical plasticity in vivo. J. Neurosci. 31, 18155-18165. doi: 10.1523/JNEUROSCI.528911.2011

Tanaka, H., Katoh, A., Oguro, K., Shimazaki, K., Gomi, H., Itohara, S., et al. (2002). Disturbance of hippocampal long-term potentiation after transient ischemia in GFAP deficient mice. J. Neurosci. Res. 67, 11-20. doi: 10.1002/jnr. 10004
Tong, X., Shigetomi, E., Looger, L. L., and Khakh, B. S. (2013). Genetically encoded calcium indicators and astrocyte calcium microdomains. Neuroscientist 19, 274291. doi: $10.1177 / 1073858412468794$

VandenDriessche, T., Ivics, Z., Izsvak, Z., and Chuah, M. K. (2009). Emerging potential of transposons for gene therapy and generation of induced pluripotent stem cells. Blood 114, 1461-1468. doi: 10.1182/blood-2009-04210427

Viale, G., Gambacorta, M., Coggi, G., Dell'Orto, P., Milani, M., and Doglioni, C. (1991). Glial fibrillary acidic protein immunoreactivity in normal and diseased human breast. Virchows Arch. A Pathol. Anat. Histopathol. 418, 339-348. doi: $10.1007 / \mathrm{BF} 01600164$

Vogel, G. (2007). Nobel prizes. A knockout award in medicine. Science 318, 178-179. doi: $10.1126 /$ science.318.5848.178

Wang, F., Smith, N. A., Xu, Q., Fujita, T., Baba, A., Matsuda, T., et al. (2012a). Astrocytes modulate neural network activity by $\mathrm{Ca}^{(2)+}$-dependent uptake of extracellular $\mathrm{K}^{+}$. Sci. Signal. 5, ra26. doi: 10.1126/scisignal.2002334

Wang, F., Xu, Q., Wang, W., Takano, T., and Nedergaard, M. (2012b). Bergmann glia modulate cerebellar Purkinje cell bistability via $\mathrm{Ca}^{2+}$-dependent $\mathrm{K}^{+}$uptake. Proc. Natl. Acad. Sci. U.S.A. 109, 7911-7916. doi: 10.1073/pnas.1120 380109

Wang, F., Smith, N. A., Xu, Q., Goldman, S., Peng, W., Huang, J. H., et al. (2013). Photolysis of caged $\mathrm{Ca}^{2+}$ but not receptor-mediated $\mathrm{Ca}^{2+}$ signaling triggers astrocytic glutamate release. J. Neurosci. 33, 17404-17412. doi: 10.1523/JNEUROSCI.2178-13.2013

Wang, X., Lou, N., Xu, Q., Tian, G. F., Peng, W. G., Han, X., et al. (2006). Astrocytic $\mathrm{Ca}^{2+}$ signaling evoked by sensory stimulation in vivo. Nat. Neurosci. 9, 816-823. doi: $10.1038 / \mathrm{nn} 1703$

Wilhelmsson, U., Li, L., Pekna, M., Berthold, C. H., Blom, S., Eliasson, C., et al. (2004). Absence of glial fibrillary acidic protein and vimentin prevents hypertrophy of astrocytic processes and improves post-traumatic regeneration. J. Neurosci. 24, 5016-5021. doi: 10.1523/JNEUROSCI.0820-04.2004

Wilson, M. H., Coates, C. J., and George, A. L. Jr. (2007). PiggyBac transposonmediated gene transfer in human cells. Mol. Ther. 15, 139-145. doi: 10.1038/sj.mt.6300028

Wilson, R. I., and Nicoll, R. A. (2002). Endocannabinoid signaling in the brain Science 296, 678-682. doi: 10.1126/science.1063545

Windrem, M. S., Nunes, M. C., Rashbaum, W. K., Schwartz, T. H., Goodman, R. A., McKhann, G. II., et al. (2004). Fetal and adult human oligodendrocyte progenitor cell isolates myelinate the congenitally dysmyelinated brain. Nat. Med. 10, 93-97. doi: $10.1038 / \mathrm{nm} 974$

Windrem, M. S., Schanz, S. J., Guo, M., Tian, G. F., Washco, V., Stanwood, N., et al. (2008). Neonatal chimerization with human glial progenitor cells can both remyelinate and rescue the otherwise lethally hypomyelinated shiverer mouse. Cell Stem Cell 2, 553-565. doi: 10.1016/j.stem.2008. 03.020

Wise, L. E., Thorpe, A. J., and Lichtman, A. H. (2009). Hippocampal CB(1) receptors mediate the memory impairing effects of delta(9)-tetrahydrocannabinol. Neuropsychopharmacology 34, 2072-2080. doi: 10.1038/npp.2009.31

Woltjen, K., Michael, I. P., Mohseni, P., Desai, R., Mileikovsky, M., Hamalainen, R., etal. (2009). piggyBac transposition reprograms fibroblasts to induced pluripotent stem cells. Nature 458, 766-770. doi: 10.1038/nature07863

Xie, A. X., Sun, M. Y., Murphy, T., Lauderdale, K., Tiglao, E., and Fiacco, T. A. (2012). Bidirectional scaling of astrocytic metabotropic glutamate receptor signaling following long-term changes in neuronal firing rates. PLoS ONE 7:e49637. doi:10.1371/journal.pone.0049637

Xie, Y., Wang, T., Sun, G. Y., and Ding, S. (2010). Specific disruption of astrocytic $\mathrm{Ca}^{2+}$ signaling pathway in vivo by adeno-associated viral transduction. Neuroscience 170, 992-1003. doi: 10.1016/j.neuroscience.2010.08.034

Yoshida, A., Yamaguchi, Y., Nonomura, K., Kawakami, K., Takahashi, Y., and Miura, M. (2010). Simultaneous expression of different transgenes in neurons and glia by combining in utero electroporation with the Tol 2 transposon-mediated gene transfer system. Genes Cells 15, 501-512. doi: 10.1111/j.1365-2443.2010.01397.x

Zhang, Y., and Barres, B. A. (2010). Astrocyte heterogeneity: an underappreciated topic in neurobiology. Curr. Opin. Neurobiol 20, 588-594. doi: 10.1016/j.conb.2010.06.005

Zidar, D. A. (2011). Endogenous ligand bias by chemokines: implications at the front lines of infection and leukocyte trafficking. Endocr. Metab. Immune Disord. Drug Targets 11, 120-131. doi: 10.2174/187153011795564160 
Zimmer, A., Zimmer, A. M., Hohmann, A. G., Herkenham, M., and Bonner, T. I. (1999). Increased mortality, hypoactivity, and hypoalgesia in cannabinoid CB1 receptor knockout mice. Proc. Natl. Acad. Sci. U.S.A. 96, 5780-5785. doi: 10.1073/pnas.96.10.5780

Conflict of Interest Statement: The authors declare that the research was conducted in the absence of any commercial or financial relationships that could be construed as a potential conflict of interest.

Received: 07 October 2013; accepted: 06 December 2013; published online: 24 December 2013.
Citation: Davila D, Thibault K, Fiacco TA and Agulhon C (2013) Recent molecular approaches to understanding astrocyte function in vivo. Front. Cell. Neurosci. 7:272. doi: $10.3389 /$ fncel.2013.00272

This article was submitted to the journal Frontiers in Cellular Neuroscience. Copyright (c) 2013 Davila, Thibault, Fiacco and Agulhon. This is an open-access article distributed under the terms of the Creative Commons Attribution License (CC BY). The use, distribution or reproduction in other forums is permitted, provided the original author(s) or licensor are credited and that the original publication in this journal is cited, in accordance with accepted academic practice. No use, distribution or reproduction is permitted which does not comply with these terms. 